\title{
Sensitivity Analysis of Hydrological Parameters in Modeling Flow and Transport in the Unsaturated Zone of Yucca Mountain
}

\author{
Keni Zhang, Yu-Shu Wu, and James E. Houseworth \\ Earth Sciences Division \\ Lawrence Berkeley National Laboratory \\ Berkeley, CA 94720, USA
}

\begin{abstract}
The unsaturated fractured volcanic deposits at Yucca Mountain have been intensively investigated as a possible repository site for storing high-level radioactive waste. Field studies at the site have revealed that there exist large variabilities in hydrological parameters over the spatial domain of the mountain. This paper reports on a systematic analysis of hydrological parameters using the site-scale 3-D unsaturated zone (UZ) flow model. The objectives of the sensitivity analyses are to evaluate the effects of uncertainties in hydrologic parameters on modeled UZ flow and contaminant transport results. Sensitivity analyses are carried out relative to fracture and matrix permeability and capillary strength (van Genuchten $\alpha$ ), through variation of these parameter values by one standard deviation from the base-case values. The parameter variation results in eight parameter sets. Modeling results for the eight UZ flow sensitivity cases have been compared with field observed data and simulation results from the base-case model. The effects of parameter uncertainties on the flow fields are discussed and evaluated through comparison of results for flow and transport. In general, this study shows that uncertainties in matrix parameters cause larger uncertainty in simulated moisture flux than corresponding uncertainties in fracture properties for unsaturated flow through heterogeneous fractured rock.
\end{abstract}

Keywords: unsaturated zone, fractured rocks, numerical modeling, hydraulic properties, Yucca Mountain 


\section{Introduction}

Site characterization studies of the unsaturated tuff at Yucca Mountain started in the late 1970s. The initial hydrological, geological, and geophysical investigations of Yucca Mountain focused on the feasibility of the site as a geological repository for storing high-level radioactive waste. These investigations led to a conceptual model of unsaturated zone (UZ) flow processes (Montazer and Wilson 1984). Soon after, theoretical studies and numerical modeling efforts were carried out to quantitatively model unsaturated groundwater flow and to simulate the natural state of the UZ underlying Yucca Mountain (e.g., Rulon et al. 1986; Pollock 1986; Tsang and Pruess; 1987; Weeks 1987). Since the 1990s, more progress was made in development and application of site-scale three-dimensional (3-D) UZ flow and transport models using the effective continuum method (ECM) approach. These models incorporated geological and hydrological complexities, such as geological layering, degree of welding, fault offsets, and distinct properties for rock matrix and fractures (Wittwer et al. 1992, 1995). Ahlers et al. (1995a, 1995b) continued development of the UZ site-scale model with increased spatial resolution. Their studies incorporated additional physical processes of gas and heat flow and introduced an inverse modeling approach for estimating model-input properties. More comprehensive UZ models were developed for the Total System Performance Assessment-Viability Assessment (TSPA-VA) (e.g., Wu et al. 1999a, 1999b; Bandurraga and Bodvarsson 1999; Ahlers et al. 1999). This new generation of UZ flow models used a more rigorous dual-permeability numerical approach for handling unsaturated flow in fractured rock and was able to better represent the observed hydrologic conditions, such as perched water bodies.

More recent UZ models include those primarily developed for the TSPA-site recommendation (SR) calculations (e.g., Wu et al. 2002a; Moridis et al. 2003; Robinson et al. 2003) and for the TSPA-license application (LA) (e.g., Wu et al. 2004a, 2004b). These TSPA-SR and TSPA-LA models have been significantly improved by using higher spatial resolution and incorporating most updated field measurements. More importantly, the newer models have taken into account coupled processes of liquid flow and geochemical transport in highly heterogeneous, unsaturated fractured porous rock, and have been applied to analyze the effect of current and future climates on radionuclide transport through the UZ system. 
This paper presents the results of our continuing effort in developing and applying flow and transport models of the Yucca Mountain UZ system. More specifically, this work documents the results of sensitivity analyses of site-scale UZ flow model parameters. The sensitivity analyses are intended to evaluate the effects of uncertainties in fracture and matrix hydrologic parameters on unsaturated zone flow and transport model results. In performing such sensitivity and uncertainty analyses, the UZ flow model (Wu et al. 2004a, 2004b) incorporates the uncertainties of the most important fracture and matrix parameters. The main emphasis of this study is on confirming the defensibility and credibility of the unsaturated zone flow model, including the effect of variability in hydrological properties, in describing unsaturated zone flow and transport processes at Yucca Mountain.

The surface net infiltration is described using a future high-infiltration scenario, called the glacial transition, mean infiltration map. The uncertainties for fracture and matrix permeabilities and van Genuchten $\alpha$ are incorporated into the analyses. Sensitivity simulations are performed using the UZ flow model by incrementing or decrementing a selected parameter by one standard deviation; this modification is performed for all the units/layers as well as faults. Each simulation adjusts one parameter only, with other parameters not changing their values from the base parameter set (the parameter set used for site-scale flow modeling, which is from field measurement and model calibrations). The parameter variation results in a total of eight parameter sets that account for the uncertainties of the four hydrological parameters. Eight new three-dimensional UZ flow fields are generated using the eight parameter sets. Then the sensitivity of the UZ model results, as well as radionuclide transport from the repository to the water table, are evaluated for these flow fields. The glacial transition, mean infiltration map, representing future climate, is used as the top boundary condition for all cases.

\section{Site Hydrogeology and Conceptual Model}

The UZ formation is between 500 and $700 \mathrm{~m}$ thick in the area of the repository and overlies a relatively flat water table. The current design places the repository in the highly fractured Topopah Spring welded tuff unit, approximately $300 \mathrm{~m}$ above the water table. Geologically, Yucca Mountain is a structurally complex system of Tertiary volcanic rock. Subsurface hydrological processes in the UZ occur in a heterogeneous environment of layered, anisotropic, and fractured volcanic rocks (Scott and Bonk 1984). These UZ volcanic formations consist of 
alternating layers of welded and nonwelded ash flow and air-fall tuffs. The primary geological formations, beginning from the land surface and progressing downward, are the Tiva Canyon, Yucca Mountain, Pah Canyon, and the Topopah Spring tuffs of the Paintbrush Group. Underlying these are the Calico Hills Formation and the Prow Pass, Bullfrog, and Tram tuffs of the Crater Flat Group (Buesch et al. 1995).

Figure 1 presents a typical geological profile along a vertical east-west transect of the northern model domain, displaying the conceptual model used in this study to analyze UZ flow patterns. As illustrated in Figure 1, the ground surface of the UZ is subject to spatially and temporally varying net infiltration pulses from precipitation, which provide the water source for deep percolation into the UZ. Surface infiltration pulses are expected to move rapidly through the top, highly fractured $\mathrm{TCw}$ unit, with little attenuation in travel times. Once it enters the PTn, percolating water may be subject to very different processes, because the PTn unit has very different hydrogeologic properties from the TCw and TSw units, which display the low porosity and intensive fracturing typical of the densely welded tuffs. In comparison, the PTn matrix has high porosity and low fracture intensity, which provides a large capacity for storing groundwater of transient percolation from the $\mathrm{TCw}$ unit. In addition, the possibility for capillary barriers exists in the PTn layers (Montazer and Wilson 1984; Wu et al. 2002b), because large contrasts in rock properties exist across the interfaces of units and inner PTn layers.

In the lower hydrogeological units of the UZ, field tests have revealed perched water in several boreholes at Yucca Mountain (Rousseau et al. 1998). These perched water locations are found to be associated with low-permeability zeolites in the $\mathrm{CHn}$ or the densely welded basal vitrophyre of the TSw unit, below the repository horizon. Therefore, a permeability-barrier conceptual model has been used to explain perched water phenomena in UZ flow modeling studies since 1996 (Wu et al. 1999b, 2002a).

Another complicating factor for UZ flow is the existence of many vertical or near-vertical faults in the UZ. These faults are also expected to play an important role in impacting percolation flux. Permeability within faults is much higher than that in the surrounding tuff (Montazer and Wilson 1984). For example, pneumatic permeability measurements taken along portions of faults reveal 
low air-entry pressures, indicating that large fracture apertures are present in the fault zones. Fault zones may act as vertical capillary barriers to lateral flow. Once water is diverted into a fault zone, however, its high permeability could facilitate rapid downward flow through the unsaturated system (Wang and Narasimhan 1987; Wu et al. 2002a). In this modeling study, faults are treated as intensively fractured zones.

In addition to possible effects of capillary and permeability barriers, field data also indicate that the geological formations at the site are more heterogeneous vertically than horizontally, such that layer-wise representations are found to provide reasonable approximations to the complex geological system. In this layer-wise approximation, model calibration results are able to match different types of observational data obtained from different locations and depths (e.g., Bandurraga and Bodvarsson 1999; Ahlers et al. 1999; Wu et al. 2002a).

As shown in Figure 1, the key conceptualizations and assumptions made in this study, as well as in the current UZ flow model, are: (1) ambient water flow in the UZ system is at a quasi-steady state condition, subject to spatially varying net infiltration on the ground surface; (2) hydrogeological units/layers are internally homogeneous, unless interrupted by faults or altered by post-depositional processes; (3) capillary barriers exist within the PTn unit, causing lateral flow; (4) perched water in the lower units results from permeability barrier effects; and (5) major faults serve as fast downward flow pathways for laterally diverted flow.

\section{Model Description}

This section describes the geological model and numerical model grids, the modeling approach

for handling fracture-matrix interaction, the numerical scheme and codes, input parameters, and boundary conditions used in the UZ flow model for this paper.

\section{Geological Model and Numerical Grid}

The geological model used for developing the UZ model grid is the current geological framework model (BSC 2004a, 2004b). Table 1 lists the geological units/layers for different hydrogeologic units and the associated UZ model numerical grid-layer information. These geologic formations have been organized into layered hydrogeologic units based primarily on the 
degree of welding (Montazer and Wilson 1984): the Tiva Canyon welded hydrogeologic unit (TCw), the PTn, the Topopah Spring welded unit (TSw), the CHn, and the Crater Flat undifferentiated unit.

The three-dimensional unsaturated zone model domain, as well as the numerical grid for this study, is shown in the plan view in Figure 2. The 3-D model encompasses approximately $40 \mathrm{~km}^{2}$ of the area over the mountain. The UZ model grid of Figure 2 was primarily designed for model calibration and simulations of three-dimensional flow fields delivered for use in calculations $(\mathrm{Wu}$ et al. 2004a). Also shown in Figure 2 are the locations of several boreholes used in model sensitivity and uncertainty analyses. Note that the model domain is selected to focus on the study area of the repository and to investigate the effects of major faults on moisture flow around and below the repository. In the numerical model grid, faults are represented in the model by vertical or inclined $30 \mathrm{~m}$ wide zones.

The three-dimensional numerical model grid, as shown in plan view in Figure 2, has 2,042 mesh columns of fracture and matrix continua and an average of 59 computational grid layers in the vertical direction. The grid has 245,506 gridblocks and 989,375 connections in a dualpermeability grid.

\section{Numerical Codes and Modeling Approach}

The model simulation results presented in this paper are carried out using the TOUGH2 code Version 1.6 (LBNL 2003; Wu et al. 1996) for unsaturated flow and the T2R3D code (LBNL 1999; Wu and Pruess 2000) for radionuclide transport. They are chosen because of their generalized capability of handling fracture and matrix interaction using the dual-permeability approach (consider fracture and matrix as two overlap continuum), which is the key for simulating unsaturated zone fluid flow in the fractured porous rock of Yucca Mountain. In particular, the dual-permeability modeling approach has been used in this study to evaluate fluid flow and tracer transport in the fracture and matrix system of the UZ system of Yucca Mountain.

As applied in this study, the traditional dual-permeability concept is first modified using an active fracture model (Liu et al. 1998) to represent fingering effects of liquid flow through fractures and to limit flow into the matrix system. In addition, the dual-permeability model is 
also modified by adding additional global fracture and matrix connections (connections between matrix and fracture gridblocks at different layers) at interfaces of TCw-PTn, PTn-TSw, and boundaries of vitric-nonvitric units to better simulate fracture and matrix flow at these transitions. Note that vitric units in the $\mathrm{CHn}$ are handled as single-porosity matrix only (i.e., the effect of fractures on flow within Calico Hills vitric zones is neglected).

\section{Boundary Conditions}

The ground surface of the mountain (or the tuff-alluvium contact in areas of significant alluvial cover) is taken as the top model boundary; the water table is treated as the bottom model boundary. Both the top and bottom boundaries of the model are treated as Dirichlet-type boundaries with specified constant, but spatially varying conditions. Surface infiltration is applied using a source term in the fracture gridblocks. Lateral boundaries, as shown in Figure 2, are treated as no-flow (closed) boundaries in the unsaturated zone flow model, which allow flow to occur only along the vertical plane. Net infiltration is used as a flux boundary condition for the UZ flow model. Figure 3 shows in plan view the spatial distribution of infiltration flux for the glacial transition mean infiltration scenario, which corresponds to a future climate (BSC 2004c). Figure 3 shows higher infiltration rates in the northern part of the model domain and along the mountain ridge east of the Solitario Canyon fault.

\section{Parameters and Uncertainties}

The key input rock and fluid-flow parameters used in the UZ model include (1) fracture and matrix properties (permeability, van Genuchten $\alpha$ and $m$ parameters, porosity, fracture and matrix interface area, and residual and satiated saturations) for each unsaturated zone model layer; (2) the thermal matrix properties; and (3) fault properties (fault parameters for each of the major hydrogeologic units (Table 1). Note that van Genuchten relative permeability and capillary pressure functions (van Genuchten 1980) are used to describe flow in both fractures and matrix in the UZ flow model. The development and estimation of these parameters are presented in the three reports (BSC 2004d, 2004e; Wu et al. 2004a).

In this study, sensitivity and uncertainty analyses use the UZ model base-case parameter set as a starting point. Experience with the UZ flow model (e.g., Wu et al., 2004a) suggests that 
permeability and van Genuchten $\alpha$ for the fractures and matrix are the most important parameters affecting UZ flow. Therefore, UZ flow sensitivity analyses were conducted by incorporating the standard deviations for these parameters given in Table 2 (BSC 2004d) into the threedimensional model, base-case parameter set of Table 3 (Wu et al. 2004a). Note that standard deviations for matrix and fracture permeability and van Genuchten $\alpha$ (Table 2) are estimated using about 700 matrix permeability and 600 fracture permeability measurements. In addition, standard deviations for $\log (\alpha)$ are calculated using a correlation with permeability for fracture and matrix systems, respectively. This is because there are insufficient $\alpha$ data points, determined from curve-fitting, for meaningful estimates of its standard deviations. The details on determination of parameter uncertainties are discussed in BSC (2004d).

Sensitivity simulations are performed using the base-case parameter set by incrementing or decrementing the value of a selected base-case parameter by one standard deviation. The parameter modification is done for all the units/layers in Tables 2 and 3. This variation in the four selected parameters leads to eight new parameter sets. Eight three-dimensional UZ flow simulations are performed to investigate the effects of uncertainty in these parameters.

\section{Simulation Results and Analyses}

The eight 3-D flow simulation scenarios and associated model input parameter sets are summarized in Table 4 for sensitivity analyses of the UZ model input parameters. In addition, Table 4 lists another simulation case, which is the base-case model scenario using the base-case parameters, for comparison in the following analyses. The results of the eight sensitivity flow simulations as well as the base-case scenario are examined and discussed in this section with comparisons of (1) matrix moisture data at two boreholes, UZ-14 and SD-12; (2) percolation behavior and flux patterns; and (3) radionuclide transport from the repository to the water table.

\section{Comparisons of simulated and measured moisture data}

Comparisons of simulated and measured matrix liquid saturations along the vertical column representing boreholes UZ-14 and SD-12 are shown in Figures 4 and 5 from the eight sensitivity and the base-case simulation scenarios. Figure 6 shows the comparison of water potentials for SD-12. As shown in Figures 4, 5, and 6, the modeled results from the nine simulations with the 
UZ flow model have similar patterns. However, the simulation results with adjusted matrix parameters show greater deviation from the base-case scenario than simulation results with modified fracture parameters. A comparison of the simulated liquid saturations from the eight simulation scenarios with the base-case results indicates:

- Simulated matrix liquid saturations decrease as matrix permeability and matrix van Genuchten $\alpha$ increase.

- Simulated matrix liquid saturations increase as matrix permeability and matrix van Genuchten $\alpha$ decrease.

- Increasing fracture van Genuchten $\alpha$ (equivalent to lowering capillarity in fractures) or a reduction in fracture permeability also results in an increase in matrix saturation, particularly, in the TSw unit.

Decreasing fracture van Genuchten $\alpha$ (equivalent to increasing capillarity in fractures) or increasing fracture permeability reduces matrix saturations in general, but the magnitude of the change is relatively small. Figure 6 shows that variation in fracture properties results in little change in matrix water potentials, while decrease in matrix permeability and matrix $\alpha$ seems to have a large impact on water potentials within the TSw unit at borehole SD-12.

\section{Percolation Fluxes and Patterns}

Percolation fluxes at the repository horizon and at the water table are analyzed using the eight simulation results (Table 4). In the analysis, the percolation flux is defined as total vertical liquid mass flux through both fractures and matrix and is converted from simulated mass flux ( $\mathrm{kg} / \mathrm{s})$ to millimeter per year $(\mathrm{mm} / \mathrm{yr})$ per unit area using a constant water density. The flux distribution at the repository horizon and at the water table are plotted and compared, for each case, to show the effect of parameter uncertainty. A statistical evaluation of the distribution of flux at the $\mathrm{TCw} / \mathrm{PTn}$ interface, the repository horizon, and water table are performed to quantify these effects.

(1) Percolation Fluxes at Repository Horizon: Because only glaq+kM and glaq-aM simulations show appreciable differences from the base-case simulation in terms of percolation fluxes, we 
will focus our discussion on these two simulations. Figures 7, 8, and 9 show three sample percolation fluxes along the repository layer for the simulated flow fields. Figure 7 presents the simulated repository fluxes from the base-case simulation (glaq_mA, Wu et al. 2004a), while Figures 8 and 9 are the cases with increased matrix permeability (glaq $+\mathrm{kM}$ ) and decreased matrix van Genutchen $\alpha$ (glaq-aM), respectively.

Comparisons of the calculated repository percolation fluxes (Figures 7, 8, and 9) with the surface infiltration maps (Figure 3) indicate that percolation fluxes at the repository, obtained by the base case and the two sensitivity simulations, are different from surface infiltration patterns, particularly, in the northern part of the model domain. Under steady-state flow conditions, percolation flux and its distribution along any horizon of the model domain would be similar to surface infiltration if there were no lateral flow. Consequently, the differences between surface infiltration and repository percolation patterns indicate the occurrence of lateral flow across the TCw, PTn, and TSw units.

Most of the lateral flow between the ground surface and the repository horizon is found to be caused by the capillary barrier effect within the PTn (Wu et al. 2004a, 2004b). The large-scale lateral flow is shown in Figure 8, corresponding to the simulation scenario in which the matrix permeability is increased by one standard deviation. In this case, the high-infiltration zones along the crest of the mountain surface appear as high-percolation-flux zones close to the Ghost Dance fault at the repository level. This is because high matrix permeability enhances capillary barrier effects and the resulting lateral flow in the PTn (Pan et al. 2004). Significant lateral flow can be seen in Figure 9, when the van Genuchten $\alpha$ parameter is reduced by a standard deviation, i.e., the capillarity of the matrix system is increased,thus enhancing the capillary barrier effect. The remaining six simulations with fracture and other matrix parameter variations are also found to be similar to Figure 7 for percolation fluxes at the repository horizon. This similarity indicates that parameter variations related to fracture properties have little impact on lateral flow through the PTn unit. These results imply that the capillary-barrier effects in the PTn are primarily controlled by the contrasts in matrix capillary properties (Wu et al. 2002).

Note that flow focusing or redistribution in the very northern part of the model domain (below the repository block) results mainly from the repository layering, where the repository horizon 
laterally intersects the low-permeability $\mathrm{CHn}$ zeolitic zones. These low-permeability zeolites provide strong permeability barriers to downward flow, shifting the major flow paths toward faults.

(2) Percolation Fluxes at the Water Table: Simulated percolation fluxes at the water table are shown for the base-case (Figure 10) and two sample new flow simulations (Figures 11 and 12). When comparing the percolation-flux patterns at the water table with those at the repository (Figures 7, 8, and 9), as well as among themselves from the eight simulation scenarios (only two examples are shown in Figures 11 and 12), we find the following:

- All the nine flow fields present similar modeled percolation patterns at the water table, as shown in Figure 10, except for the cases with a matrix permeability increase (glaq+kM, Figure 11) and a matrix van Genuchten $\alpha$ decrease (glaq-aM, Figure 12).

- In the northern half of the model domain, all nine flow fields are nearly the same. Because of the significant impact of faults, perched water and lower-permeability zeolitic units, the flow is focused mainly into major faults in the north.

- In the southwest-corner portion of the model domain, the area where nonfractured vitric zones are located within the $\mathrm{CHn}$ unit, no differences appear between the modeled water table fluxes using modified fracture properties, because there are no fractures within the vitric units. This is simply the result of the conceptual model of nonfractured vitric zones, with flow in the $\mathrm{CHn}$ vitric independent of fracture properties.

- Changes in matrix properties seem to have more impact on flux patterns in the southern half of the model domain. Even in these cases, however, similar flux patterns are obtained for increased matrix permeability and decreased matrix van Genuchten $\alpha$. The only obvious differences occur in water-table flux distributions for the two cases, as shown in Figures 11 and 12. Larger matrix permeability and smaller van Genuchten $\alpha$ (stronger matrix capillarity) within the vitric and zeolitic zones result in a significant difference between the flux patterns at the repository level and at the water table, because these parameter changes cause changes in capillary barrier conditions and lateral flow above these zones. 
(3) Fracture and Matrix Flow Components and Statistics: Table 5 lists percentages of vertical fracture and matrix flow components (not including flux in faults) and fault flow over the entire model domain and within the repository footprint, a smaller area covering the repository drifts only (Figure 2). The statistics are calculated at three horizons: (1) the TCw/PTn interface or the top of the PTn unit, (2) the repository level, and (3) the water table. Fracture and matrix flow percentages are computed for the nonfault zones only (i.e., excluding the vertical flow through all the faults), while fault flow percentages represent total vertical fracture and matrix flux through fault blocks over the entire model layer or the repository footprint at the three horizons. The percentages of fracture, matrix, and fault flow components sum to $100 \%$. These statistics are calculated from vertical flow along each grid column, using the flow fields from the eight parameter-sensitivity simulations. In addition, Table 5 includes the base-case simulation scenario using the base-case fracture and matrix parameters (glaq_mA) for comparison (Wu et al. 2004a).

A comparison between the computed flux data (Table 5) on fracture, matrix, and fault flow components among the eight parameter sensitivity simulations, as well as the base-case (glaq_mA) results, shows the following:

- At the top of the PTn or TCw/PTn interface, the flux distribution is essentially similar to surface infiltration. Fracture and matrix flow components and fault flow percentage are very similar for all nine (eight sensitivity and one base-case) simulations. The results show that fracture flow dominates both over the small area within the repository footprint and the entire model domain. Fault flow consists of nearly $4 \%$ over the model domain, while over the repository footprint, fault flow takes about $1.4 \%$ only. For the eight new simulations, the only differences are that the case with increased matrix permeability (glaq $+\mathrm{kM})$ has slightly large matrix flow components compared to other cases, while the cases with decreased matrix permeability (glaq-kM) and increased van Genuchten $\alpha$ (glaq $+\mathrm{aM})$ show some reduction in matrix flow portions. Note that in all cases, nonfault matrix flow within the repository footprint is practically zero at the TCw/PTn interface, showing the dominance of fracture flow within the TCw. 
- At the repository level, compared with the base-case (glaq_mA) results, a significant increase occurs in matrix flow components when the matrix permeability is increased (glaq $+\mathrm{kM})$. The matrix flow increases from $5.5 \%$ to $16.8 \%$ over the model domain and from $0.2 \%$ to $9.5 \%$ within the repository footprint, while fracture flow decreases from $70.2 \%$ to $60.5 \%$ over the model domain and from $98.5 \%$ to $87.9 \%$ inside the footprint. In addition, a decrease in matrix van Genuchten $\alpha$ leads to a large increase in matrix flow. However, fault flow percentages are only slightly impacted by any variations in the fracture and matrix parameters. Within the repository footprint, fault flow consists of only 1-2\% of total flow, except in the cases of increased matrix permeability (glaq $+\mathrm{kM})$ and decreased fracture van Genuchten $\alpha$ (glaq-aF), which have more than $2 \%$ fault flow.

- At the water table, fracture and matrix flow components and fault flow from the eight sensitivity simulations show more differences from those of the base case (glaq_mA), as compared with the two horizons above. Larger differences can be seen in the flux within the repository footprint. Matrix flow increases from $42.3 \%$ for the base case to $55.9 \%$ when matrix permeability is increased by one standard deviation (glaq $+\mathrm{kM})$. This increase in matrix flow is accompanied by a corresponding decrease in fault flow from $49.9 \%$ to $37.9 \%$. When matrix permeability is decreased by one standard deviation (glaq-kM), fracture flow increases from $7.8 \%$ to $21.6 \%$. Fracture flow also increases significantly when fracture permeability is increased by one standard deviation $(\mathrm{glaq}+\mathrm{kF})$. Fracture flow increases three times, from $7.8 \%$ to $23.7 \%$, with a corresponding decrease in matrix flow.

- Overall, fracture flow is dominant above the PTn unit, accounting for about $95 \%$ of the total percolation fluxes over the entire model layer. Fracture flow percentage is over $98 \%$ within the repository footprint at the TCw/PTn interface. At the repository level, nonfault fracture flow reduces to $60 \%$ to $70 \%$ and matrix flow increases from $1 \%$ at the top of the PTn to $5 \%$ to $8 \%$ at the repository level. In comparison, fault flow increases from less than $4 \%$ at the $\mathrm{TCw} / \mathrm{PTn}$ interface to $23 \%$ to $26 \%$ at repository horizon, indicating significant lateral flow and diversion occurs within the PTn unit. At the water table, fault flow makes up about 50\% of the total flow over the entire model domain and within the repository footprint, except when matrix permeability increases by one standard deviation, in which case fault flow is about $38 \%$. A comparison of fault flow at the water table with that at the repository level 
indicates that significant lateral diversion or flow focusing into faults also occurs during flow through $\mathrm{CHn}$, because of the existence of perched water and low-permeability zeolitic zones within this unit. Secondly, over the nonfaulted zone, matrix flow is larger than fracture flow at the water table, due to dominant matrix flow through nonfractured vitric zones.

(4) Distributions of Percolation Fluxes within the Repository: Percolation fluxes within the repository footprint at the repository horizon were further analyzed using frequency distribution plots for the percentage of the repository area subject to a particular, normalized percolation rate. The normalized flux rates are determined by dividing percolation rates by the model domain average infiltration rate of $17.02 \mathrm{~mm} / \mathrm{yr}$. Figures 13 through 17 show the frequency distribution of normalized percolation flux within the repository footprint at the repository horizon for the eight sensitivity flow simulations as well as for the base case. Analysis of percolation flux distribution within the repository footprint will help in assessing flow-focusing phenomena at the footprint. The percolation frequency distributions, as presented in the figures, provide insight into flow-redistribution phenomena at the repository.

Figures 14 through 17 show similar patterns in the flux-area frequency distribution based on the eight sensitivity simulation results, compared to that of the base case shown in Figure 13. The highest flux frequency for all distributions occurs for a normalized flux less than 1.

A normalized flux of about 0.2 to 1.0 occurs over about $50 \%$ to $60 \%$ of the repository area. The areas with normalized percolation fluxes greater than three comprise a very small portion, constituting less than a few percent of the total repository area.

Despite the similarity in flux frequency distributions, a close examination of the plots reveals certain differences, as follows:

- The two cases with decreased matrix permeability (glaq-kM) and increased matrix van Genuchten $\alpha(\mathrm{glaq}+\mathrm{aM})$ have a highest frequency percentage in about $14 \%$ of the area, while the corresponding two cases with increased matrix permeability (glaq $+\mathrm{kM})$ and decreased matrix van Genuchten $\alpha$ (glaq-aM) show highest frequency in $18 \%$ of the area (see Figure 14 and 15). 
- Flux distribution patterns for the four cases with fracture property variations (Figures 16 and 17) show less sensitivity. In contrast to the matrix parameter changes, however, the highest flux frequencies occur for the two cases with decreased fracture permeability (glaq-kF) and increased fracture van Genuchten $\alpha(\mathrm{glaq}+\mathrm{aF})$, covering $18 \%$ of the area. The cases that have increased fracture permeability $(\mathrm{glaq}+\mathrm{kF})$ and decreased fracture van Genuchten $\alpha$ (glaq-aF) show lower frequency.

- In all sensitivity simulations, increasing permeability results in very similar flux-frequency patterns to decreasing van Genuchten $\alpha$, and decreasing permeability leads to very similar results to increasing van Genuchten $\alpha$.

\section{Radionuclide Transport from Repository to Water Table}

Results of tracer transport simulation can provide additional insight into flow patterns below the repository. Tracer transport simulations are carried out using the eight sensitivity cases and basecase flow fields. Tracer-transport times are estimated by conservative (nonsorbing) and reactive (sorbing) tracer simulations, in which tracers are tracked after release from the repository and transported to the water table. Transport simulations are run to 1,000,000 years for the nine 3-D, steady-state flow fields. A uniform mass of tracer is released into the repository fracture elements at the beginning of the simulation. In addition, hydrodynamic/mechanical dispersion through the fracture-matrix system is ignored, because past studies have indicated that mechanical dispersion has an insignificant effect (Wu et al. 2004a). A constant molecular diffusion coefficient of $3.2 \times 10^{-11} \mathrm{~m}^{2} / \mathrm{s}$ is used for the conservative component of technetium (Tc), and $1.6 \times 10^{-10} \mathrm{~m}^{2} / \mathrm{s}$ is selected for the reactive component of neptunium $(\mathrm{Np})$. For the conservative tracer, $K_{d}=0$, and for the reactive tracer, $K_{d}=4 \mathrm{cc} / \mathrm{g}$ for zeolitic matrix, $K_{d}=1$ cc/g for other matrix rock in TSw and CHn units, and $\mathrm{K}_{\mathrm{d}}=0$ for all fractures and other units. Tracer transport modeling was conducted with the T2R3D code (Wu and Pruess 2000) using the same flow model grid (Figure 2) and the same dual-permeability approach for fracture-matrix interaction. In transport simulation, isothermal, unsaturated, steady-state flow fields of the nine simulations were used as direct input to the T2R3D. 
Figures 18 and 19 show fractional mass breakthrough curves of normalized cumulative radionuclide mass arriving at the water table for the conservative and reactive cases respectively. The fractional mass breakthrough in the two figures is defined as cumulative radionuclide mass arriving at the water table over the entire model bottom boundary over time, normalized by the total initial mass released from the entire repository. The two figures present the behavior of breakthrough at the water table for conservative and reactive tracers under the nine simulated UZ flow fields of Table 4.

Figure 18 shows conservative tracer-transport simulation results, indicating that large differences exist in breakthrough curves only in the three scenarios (glaq+kM, glaq-kM and glaq+aM, i.e., modified matrix properties), when compared to the base case and the eight sensitivity simulation results. The remaining five simulations show similar transport results to the base case. With the increase in matrix permeability, tracer transport time is consistently longer than the base case. This is because of the significant increase in matrix flow on both repository and water table horizons (Table 5) for the cases with increased matrix permeability. With increased matrix $\alpha$, the early tracer transport times $(<1,000$ years) are longer than the base case.

As shown in Figure 19, there are more differences in reactive tracer transport times with the eight new flow fields than with the base case. In contrast to the conservative tracer transport, modeling results with modified fracture properties tend to provide shorter transport times, while those with matrix property changes give longer transport times. Overall, as shown in Figures 18 and 19, varying matrix properties seems to cause more changes in tracer transport times than varying fracture parameters.

\section{Concluding Remarks}

This paper presents sensitivity analyses of the unsaturated zone flow model results to model input parameters. The sensitivity analyses are conducted by varying fracture and matrix properties of the site-scale UZ flow model, using the statistical data of standard deviation from measurements. Specifically, the sensitivity analyses are intended to estimate the effect of 
uncertainties in fracture and matrix hydrologic parameters on unsaturated zone flow and transport model predictions.

Modeling studies for sensitivity analyses of the UZ flow model input parameters are conducted to evaluate how best to account for uncertainties in four key parameters: permeability and van Genuchten $\alpha$ for both fractures and matrix. In particular, sensitivity simulations are performed using standard deviations associated with the three-dimensional model, base-case parameter set, by incrementing and decrementing a selected parameter by one standard deviation for all units/layers and faults. These parameter variations result in a total of eight parameter sets. Therefore, eight new three-dimensional UZ flow fields are generated to account for the uncertainties in the four hydrological parameters for the fractures and the matrix. The mean glacial transition infiltration scenario used in this paper corresponds to a potential future climate with higher average surface infiltration than the present-day climate. The three-dimensional UZ flow model, based on the current geological framework model, is used to incorporate sitespecific data for Yucca Mountain and implement updated hydrological properties.

Modeling results of the eight three-dimensional flow simulations have been compared with observed borehole moisture water data and among themselves. In addition, the eight sensitivity simulations are also compared with the base-case simulation results that use the base-case property set. The eight sensitivity flow fields cover a wide range of variability in modeled liquid saturation, water potential, and percolation flux. The comparisons show that the eight modeled results, even though showing some similarities with the measured saturation and water-potential profiles, as well as simulated results with the base-case parameter set, are different from the base-case simulation results. In general, the eight new modeling results indicate that uncertainties in matrix parameters cause larger uncertainty in simulated liquid saturation, water potential, and percolation flux than corresponding uncertainty in fracture properties.

Comparisons of the repository percolation fluxes obtained by the eight sensitivity simulations and the base-case flow field indicate that percolation fluxes at the repository are generally similar to each other. The only major differences are predicted when matrix permeability is increased by one standard deviation or matrix van Genuchten $\alpha$ is decreased by one standard deviation. The modeled percolation fluxes also show little sensitivity to changes in fracture parameters. 
Simulated percolation fluxes at the water table from the eight sensitivity simulations (as compared with the base case) show similar percolation flux patterns, except in the two cases of increased matrix permeability and decreased matrix van Genuchten $\alpha$. For these cases, the watertable flux shows some differences in the southwest portion of the model domain, where nonfractured vitric zones of the $\mathrm{CHn}$ unit intersect the water table. In the northern half of the model domain, all the eight flow fields at the water table are nearly the same as the base case. In all cases, the lower-permeability zeolitic units in the north cause lateral flow, which focuses flow into fractures and results in the formation of perched water bodies. Similarly to the repositorylevel fluxes, uncertainty in fracture properties has little impact on flow patterns at the water table.

At the top of the PTn unit, fracture and matrix flow components and fault flow percentage are very similar for all the eight sensitivity cases, and are comparable to the base-case simulation results. In all cases, fracture flow dominates, both within the repository footprint and over the entire model domain. At the repository level, matrix flow components from the six sensitivity simulations out of the eight simulations show similar fracture and matrix flow components compared to the base case. The two exceptional cases are those with increased matrix permeability and decreased matrix van Genuchten $\alpha$, which predict a significant increase in matrix flow and a corresponding decrease in fracture flow. Large changes in simulated fracture and matrix flow components at the water table are shown by the statistics from the eight sensitivity results within the repository footprint, when compared with the base case. The most significant change is the case with increased matrix permeability.

In terms of impacting radionuclide transport from repository to water table, conservative tracer transport shows longer breakthrough times with modified matrix properties than the base case, with little sensitivity to variation in fracture properties. For reactive tracer transport, the sensitivity results are more variable. Delayed initial breakthrough relative to the base case is found for the sensitivity cases with decreased matrix permeability and increase matrix van Genuchten $\alpha$. At later times, delayed breakthrough relative to the base case is found only for the sensitivity case with increased matrix permeability. Similar to flow patterns, variations in matrix properties have a greater effect on tracer transport times than variations in fracture properties. 
The modeling sensitivity analyses in this paper provide a systematic evaluation of how uncertainty in fracture and matrix parameters affects simulated flow and transport results in the Yucca Mountain UZ using the site-scale flow and transport model. Even though the investigations are site-specific, many insights obtained from this study may also be applicable to other sites featuring unsaturated fractured rock, as long as fracture permeability is much higher than matrix permeability at those sites, and net surface infiltration rates are relatively low. Under such conditions, fracture transmissivity is many orders of magnitude higher than ambient infiltration, and changes in fracture properties will then have little impact on unsaturated water flow. Note that there are certain limitations to the current modeling studies, and one significant limitation to this paper is that the sensitivity analyses are based on a limited number of (eight or nine) 3-D simulation results with respect to four fracture-matrix parameters only. In addition, the site-scale UZ flow model, on which the modeling analyses are based, uses a volume-averaging numerical approach that does not incorporate small-scale heterogeneity. Future modeling efforts, such as using Monte Carlo simulations, may be directed towards resolving some of these issues.

\section{Acknowledgments}

The authors would like to thank the anonymous reviewers for their critical comments. Thanks are also due to Hui-Hai Liu for his help and contribution to estimating parameter uncertainties. This work was supported by the Director, Office of Civilian Radioactive Waste Management, U.S. Department of Energy, through Memorandum Purchase Order EA9013MC5X between Bechtel SAIC Company, LLC, and the Ernest Orlando Lawrence Berkeley National Laboratory (Berkeley Lab). The support is provided to Berkeley Lab through the U.S. Department of Energy Contract No. DE-AC03-76SF00098

\section{References}

Ahlers CF, Bandurraga TM, Bodvarsson GS, Chen G, Finsterle S, Wu YS (1995a) Summary of model calibration and sensitivity studies using the LBNL/USGS three-dimensional unsaturated zone site-scale model, Yucca Mountain Site Characterization Project Report, Lawrence Berkeley National Laboratory, Berkeley, CA

Ahlers CF, Bandurraga TM, Bodvarsson GS, Chen G, Finsterle S, Wu YS (1995b) Performance analysis of the LBNL/USGS three-dimensional unsaturated zone site-scale model, Yucca Mountain Project Milestone 3GLM105M, Lawrence Berkeley National Laboratory, Berkeley, CA 
Ahlers CF, Finsterle S, and Bodvarsson GS (1999) Characterization and prediction of subsurface pneumatic response of at Yucca Mountain, Nevada, Journal of Contaminant Hydrology, 38 $(1-3), 47-68$

Bandurraga TM, Bodvarsson GS (1999) Calibrating hydrogeologic properties for the 3-D sitescale unsaturated zone model of Yucca Mountain, Nevada Journal of Contaminant Hydrology, 38 (1-3), 25-46

BSC (Bechtel SAIC Company) (2004a) Geologic framework model (GFM2000). MDL-NBSGS-000002 REV 02, Las Vegas, Nevada, Bechtel SAIC Company

BSC (Bechtel SAIC Company) (2004b) Development of numerical grids for UZ flow and transport modeling. ANL-NBS-HS-000015 REV 02, Las Vegas, Nevada: Bechtel SAIC Company

BSC (Bechtel SAIC Company) (2004c) Simulation of net infiltration for present-day and potential future climates. MDL-NBS-HS-000023 REV 00, Las Vegas, Nevada: Bechtel SAIC Company

BSC (Bechtel SAIC Company) (2004d) Calibrated properties model. MDL-NBS-HS-000003 REV 02, Las Vegas, Nevada: Bechtel SAIC Company

BSC (Bechtel SAIC Company) (2004e) Analysis of hydrologic properties data, ANL-NBS-HS000042 REV 00. Las Vegas, Nevada: Bechtel SAIC Company

Buesch DC, Spengler RW, Moyer TC, Geslin JK (1995) Nomenclature and macroscopic identification of lithostratigraphic units of the Paintbrush group exposed at Yucca Mountain, Nevada, Report USGS OFR 94-469, U. S. Geological Survey

LBNL (Lawrence Berkeley National Laboratory) (1999) Software code: T2R3D. V1.4, Earth Sciences Division, Lawrence Berkeley National Laboratory, Berkeley, California

LBNL (Lawrence Berkeley National Laboratory) (2003) Software code: TOUGH2. V1.6, Earth Sciences Division, Lawrence Berkeley National Laboratory, Berkeley, California

Liu HH, Doughty C, Bodvarsson GS (1998) An active fracture model for unsaturated flow and transport in fractured rocks, Water Resources Research, 34, 2633-2646

Montazer P. Wilson WE (1984) Conceptual hydrologic model of flow in the unsaturated zone, Yucca Mountain, Nevada. Water-Resources Investigations Report 84-4345, Lakewood, Colorado: U.S. Geological Survey

Moridis GJ, Hu Q, Wu YS, Bodvarsson GS (2003) Preliminary 3-D site-scale studies of radioactive colloid transport in the unsaturated zone at Yucca Mountain, Nevada, Journal of Contaminant Hydrology, 60, 251-286

Pan L, Wu YS, Zhang K (2004) A modeling study of flow diversion and focusing in unsaturated fractured rock, Vadose Zone Journal, 3, 233-246 
Pollock DW (1986) Simulation of fluid flow and energy transport processes associated with high-level radioactive waste disposal in unsaturated alluvium, Water Resources Research, $22(5), 765-775$

Robinson BA, Li C, Ho CK (2003) Performance assessment model development and analysis of radionuclide transport in the unsaturated zone, Yucca Mountain, Nevada, Journal of Contaminant Hydrology, 62-63, 249-268

Rousseau JP, Kwicklis EM, Gillies C (eds) (1998) Hydrogeology of the unsaturated zone, North Ramp area of the exploratory studies facility, Yucca Mountain, Nevada, U.S. Geological Survey, Water-Resources Investigations 98-4050

Rulon J, Bodvarsson GS Montazer P (1986) Preliminary numerical simulations of groundwater flow in the unsaturated zone, Yucca Mountain, Nevada, LBL-20553, Lawrence Berkeley National Laboratory, Berkeley, CA

Scott RB, Bonk J (1984) Preliminary geologic map of Yucca Mountain, Nye County, Nevada, with geologic sections, Report USGS OFR-84-494, US Geological Survey

Tsang YW, Pruess K (1987) A study of thermally induced convection near a high-level nuclear waste repository in partially saturated fracture tuff, Water Resources Research, 23 (10), 1958-1966

van Genuchten MTh (1980) A closed-form equation for predicting the hydraulic conductivity of unsaturated soils, Soil Sci. Soc. Amer. J., 44(5), 892-898

Wang JS, Narasimhan TN (1987) Hydrologic modeling of vertical and lateral movement of partially saturated fluid flow near a fault zone at Yucca Mountain, SAND87-7070, Sandia National Laboratories and LBL-23510, Lawrence Berkeley National Laboratory, Berkeley, $\mathrm{CA}$

Weeks EP (1987) Effects of topography on gas flow in unsaturated fractured rock: Concepts and observations, flow and transport through unsaturated rock (D.D. Evens and T.J. Nicholson, eds.), geophysical Monograph 42, American Geophysical Union, Washington, D.C., 165170

Wittwer C, Chen G, Bodvarsson GS, Chornack M, Flint A, Flint, Kwicklis E, Spengler R (1995) Preliminary development of the LBL/USGS three-dimensional site-scale model of Yucca Mountain, Nevada, LBL-37356, Lawrence Berkeley National Laboratory, Berkeley, CA

Wittwer C, Bodvarsson GS, Chornack MP, Flint A, Flint L, Lewis BD, Spengler RW, Rautman CA (1992) Design of a three-dimensional site-scale model for the unsaturated zone at Yucca Mountain, Nevada, High Level Radioactive Waste Management, Proceedings of the Third International Conference, Las Vegas, Nevada, April 12-16, 1992, 263-271

Wu YS, Ahlers CF, Fraser P, Simmons A, Pruess K (1996) Software Qualification Of Selected TOUGH2 Modules, Report LBL-39490; UC-800, Lawrence Berkeley National Laboratory, Berkeley, CA 
Wu YS, Haukwa C, Bodvarsson GS (1999a) A site-scale model for fluid and heat flow in the unsaturated zone of Yucca Mountain, Nevada, Journal of Contaminant Hydrology,. 38 (13), 185-217

Wu YS, Ritcey AC, Bodvarsson GS (1999b) A modeling study of perched water phenomena in the unsaturated zone at Yucca Mountain, Journal of Contaminant Hydrology, 38 (1-3), $157-184$

Wu YS, Pruess K (2000) Numerical simulation of non-isothermal multiphase tracer transport in heterogeneous fractured porous media, Advances in Water Resources, 23, 699-723

Wu YS, Pan L, Zhang W, Bodvarsson GS (2002a) Characterization of flow and transport processes within the unsaturated zone of Yucca Mountain, Nevada, Journal of Contaminant Hydrology, 54, 215-247

Wu YS, Zhang W Pan L, Hinds J, Bodvarsson GS (2002b) Modeling capillary barriers in unsaturated fractured rock, Water Resources Research, 38 (11), 35-1-35-11

Wu YS, Lu G, Zhang K, Zhang G, Liu HH, Xu T, Sonnenthal EL (2004a) UZ flow models and submodels, Report MDL-NBS-HS-000006 REV02, Berkeley, CA, Lawrence Berkeley National Laboratory, Las Vegas, Nevada, CRWMS M\&O

Wu YS, Lu G, Zhang K, Bodvarsson GS (2004b) A mountain-scale model for characterizing unsaturated flow and transport in fractured tuffs of Yucca Mountain, Vadose Zone Journal, Vol. 3, pp.796-805 
Table 1. Lithostratigraphy, unsaturated zone model layer, and hydrogeological unit correlation used in the Unsaturated Zone Flow Model and Submodels

\begin{tabular}{|c|c|c|c|}
\hline Major Unit & $\begin{array}{c}\text { Lithostratigraphic } \\
\text { Nomenclature }\end{array}$ & $\begin{array}{l}\text { UZ Model Grid } \\
\text { Unit/Layer }^{\mathrm{a}}\end{array}$ & $\begin{array}{c}\text { Hydrogeological } \\
\text { Unit }^{\mathrm{b}}\end{array}$ \\
\hline \multirow{5}{*}{$\begin{array}{l}\text { Tiva Canyon welded } \\
\text { (TCw) }\end{array}$} & Tpcr & tcw11 & CCR, CUC \\
\hline & Tpcp & tcw12 & CUL, CW \\
\hline & TpcLD & & \\
\hline & Tpcpv3 & \multirow[t]{2}{*}{ tcw13 } & \multirow[t]{2}{*}{ CMW } \\
\hline & Tpcpv2 & & \\
\hline \multirow{10}{*}{$\begin{array}{l}\text { Paintbrush nonwelded } \\
\text { (PTn) }\end{array}$} & Tpcpv1 & ptn21 & CNW \\
\hline & Tpbt4 & \multirow[t]{2}{*}{ ptn22 } & \multirow[t]{2}{*}{ BT4 } \\
\hline & \multirow[t]{3}{*}{ Tpy (Yucca) } & & \\
\hline & & ptn23 & TPY \\
\hline & & ptn24 & BT3 \\
\hline & Tpbt3 & & \\
\hline & Tpp (Pah) & ptn25 & TPP \\
\hline & Tpbt2 & \multirow[t]{3}{*}{ ptn26 } & \multirow[t]{3}{*}{ BT2 } \\
\hline & Tptrv3 & & \\
\hline & Tptrv2 & & \\
\hline \multirow{10}{*}{$\begin{array}{l}\text { Topopah Spring welded } \\
\text { (TSw) }\end{array}$} & Tptrv1 & tsw31 & TC \\
\hline & Tptrn & tsw32 & TR \\
\hline & Tptrl, Tptf & tsw33 & TUL \\
\hline & Tptpul, RHHtop & & \\
\hline & Tptpmn & tsw34 & TMN \\
\hline & Tptpll & tsw35 & TLL \\
\hline & Tptpln & tsw36 & $\begin{array}{l}\text { TM2 (upper 2/3 of } \\
\text { Tptpln) }\end{array}$ \\
\hline & & tsw37 & $\begin{array}{l}\text { TM1 (lower } 1 / 3 \text { of } \\
\text { Tptpln) }\end{array}$ \\
\hline & Tptpv3 & tsw38 & PV3 \\
\hline & Tptpv2 & tsw39 (vit, zeo) & PV2 \\
\hline \multirow{14}{*}{$\begin{array}{l}\text { Calico Hills nonwelded } \\
\text { (CHn) }\end{array}$} & Tptpv1 & \multirow[t]{2}{*}{ ch1 (vit, zeo) } & \multirow{2}{*}{$\begin{array}{l}\text { BT1 or } \\
\text { BT1a (altered) }\end{array}$} \\
\hline & Tpbt1 & & \\
\hline & \multirow{4}{*}{$\begin{array}{l}\text { Tac } \\
\text { (Calico) }\end{array}$} & ch2 (vit, zeo) & \multirow{4}{*}{$\begin{array}{l}\mathrm{CHV} \text { (vitric) } \\
\text { or } \\
\mathrm{CHZ} \text { (zeolitic) }\end{array}$} \\
\hline & & ch3 (vit, zeo) & \\
\hline & & ch4 (vit, zeo) & \\
\hline & & ch5 (vit, zeo) & \\
\hline & Tacbt (Calicobt) & ch6 (vit, zeo) & BT \\
\hline & Tcpuv (Prowuv) & pp4 & PP4 (zeolitic) \\
\hline & Tcpuc (Prowuc) & pp3 & PP3 (devitrified) \\
\hline & Tcpmd (Prowmd) & \multirow[t]{2}{*}{ pp2 } & \multirow[t]{2}{*}{ PP2 (devitrified) } \\
\hline & Tcplc (Prowlc) & & \\
\hline & Tcplv (Prowlv) & \multirow[t]{3}{*}{$\mathrm{pp} 1$} & \multirow[t]{3}{*}{ PP1 (zeolitic) } \\
\hline & Tcpbt (Prowbt) & & \\
\hline & Tcbuv (Bullfroguv) & & \\
\hline
\end{tabular}




\begin{tabular}{|c|c|c|c|}
\hline \multirow{11}{*}{$\begin{array}{l}\text { Crater Flat undifferentiated } \\
\text { (CFu) }\end{array}$} & Tcbuc (Bullfroguc) & \multirow[t]{3}{*}{ bf3 } & \multirow[t]{3}{*}{ BF3 (welded) } \\
\hline & Tcbmd (Bullfrogmd) & & \\
\hline & Tcblc (Bullfroglc) & & \\
\hline & Tcblv (Bullfroglv) & \multirow[t]{3}{*}{ bf2 } & \multirow[t]{3}{*}{ BF2 (nonwelded) } \\
\hline & Tcbbt (Bullfrogbt) & & \\
\hline & Tctuv (Tramuv) & & \\
\hline & Tctuc (Tramuc) & \multirow[t]{3}{*}{ tr3 } & \multirow[t]{3}{*}{ Not Available } \\
\hline & Tctmd (Trammd) & & \\
\hline & Tctlc (Tramlc) & & \\
\hline & Tctlv (Tramlv) & \multirow[t]{2}{*}{ tr2 } & \multirow[t]{2}{*}{ Not Available } \\
\hline & Tctbt (Trambt) and below & & \\
\hline
\end{tabular}

${ }^{a}$ Defined by the rock material type, represented by the code name, for grid layers or blocks belonging to the same rock unit.

${ }^{\mathrm{b}}$ Hydrogeological units or layers defined for the UZ model exclude alluvial covers. The top model boundary is at the ground surface of the mountain (or the tuff-alluvium contact in areas of significant alluvial covers). 
Table 2. Uncertainties (or standard deviations) of model parameters

\begin{tabular}{|c|c|c|c|c|}
\hline \multirow{2}{*}{ Model layer } & \multicolumn{2}{|c|}{ Matrix Property } & \multicolumn{2}{|c|}{ Fracture Property } \\
\hline & $\sigma \log \left(k_{M}\right)$ & $\sigma \log \left(\alpha_{M}\right)$ & $\sigma \log \left(\mathrm{k}_{\mathrm{F}}\right)$ & $\sigma \log \left(\alpha_{\mathrm{F}}\right)$ \\
\hline Tcw11 & 0.47 & 0.24 & 1.15 & 0.58 \\
\hline Tcw12 & 2.74 & 1.37 & 0.78 & 0.39 \\
\hline Tcw13 & 2.38 & 1.19 & 1.15 & 0.58 \\
\hline ptn21 & 2.05 & 1.03 & 0.88 & 0.44 \\
\hline ptn22 & 1.41 & 0.71 & 0.20 & 0.10 \\
\hline ptn23 & 0.64 & 0.32 & 0.20 & 0.10 \\
\hline ptn24 & 1.09 & 0.55 & 1.15 & 0.58 \\
\hline ptn25 & 0.39 & 0.20 & 0.10 & 0.05 \\
\hline ptn26 & 1.12 & 0.56 & 1.15 & 0.58 \\
\hline Tsw31 & 3.02 & 1.51 & 1.15 & 0.58 \\
\hline Tsw32 & 0.94 & 0.47 & 0.66 & 0.33 \\
\hline Tsw33 & 1.61 & 0.81 & 0.61 & 0.31 \\
\hline Tsw34 & 0.97 & 0.49 & 0.47 & 0.24 \\
\hline Tsw35 & 1.65 & 0.83 & 0.75 & 0.38 \\
\hline Tsw36 & 3.67 & 1.84 & 0.54 & 0.27 \\
\hline Tsw37 & 3.67 & 1.84 & 0.28 & 0.14 \\
\hline Tsw38 & 1.57 & 0.79 & 1.15 & 0.58 \\
\hline tswz (zeolitic portion of tsw39) & 2.74 & 1.37 & 1.15 & 0.58 \\
\hline tswv (vitric portion of tsw39) & 1.38 & 0.69 & $\mathrm{a}$ & $\mathrm{a}$ \\
\hline $\operatorname{ch} 1 z$ & 2.74 & 1.37 & 1.15 & 0.58 \\
\hline $\operatorname{ch} 1 v$ & 1.11 & 0.56 & $\mathrm{a}$ & $\mathrm{a}$ \\
\hline $\operatorname{ch} 2 v$ & 1.62 & 0.81 & a & $\mathrm{a}$ \\
\hline $\operatorname{ch} 3 v$ & 1.62 & 0.81 & $\mathrm{a}$ & $\mathrm{a}$ \\
\hline $\operatorname{ch} 4 v$ & 1.62 & 0.81 & $\mathrm{a}$ & $\mathrm{a}$ \\
\hline $\operatorname{ch} 5 \mathrm{v}$ & 1.62 & 0.81 & $\mathrm{a}$ & $\mathrm{a}$ \\
\hline $\operatorname{ch} 6 \mathrm{v}$ & 1.11 & 0.56 & $\mathrm{a}$ & $\mathrm{a}$ \\
\hline $\operatorname{ch} 2 z$ & 0.91 & 0.46 & 1.15 & 0.58 \\
\hline $\operatorname{ch} 3 z$ & 0.91 & 0.46 & 1.15 & 0.58 \\
\hline $\operatorname{ch} 4 z$ & 0.91 & 0.46 & 1.15 & 0.58 \\
\hline $\operatorname{ch} 5 z$ & 0.91 & 0.46 & 1.15 & 0.58 \\
\hline $\operatorname{ch} 6 z$ & 2.05 & 1.03 & 1.15 & 0.58 \\
\hline $\mathrm{pp} 4$ & 2.74 & 1.37 & 1.15 & 0.58 \\
\hline pp3 & 0.75 & 0.38 & 1.15 & 0.58 \\
\hline $\mathrm{pp} 2$ & 1.18 & 0.59 & 1.15 & 0.58 \\
\hline $\mathrm{pp} 1$ & 1.52 & 0.76 & 1.15 & 0.58 \\
\hline bf3 & 1.64 & 0.82 & 1.15 & 0.58 \\
\hline bf2 & 1.52 & 0.76 & 1.15 & 0.58 \\
\hline
\end{tabular}

a Conceptual model does not include fractures in these model layers

b Fault property set does not include matrix properties. 
Table 3 Base-case parameters for the UZ Flow and Transport Model

\begin{tabular}{|c|c|c|c|c|c|c|c|}
\hline $\begin{array}{l}\text { Model } \\
\text { Layer }\end{array}$ & $\begin{array}{c}k_{M} \\
\left(m^{2}\right)\end{array}$ & $\begin{array}{c}\alpha_{M} \\
(1 / P a)\end{array}$ & $\begin{array}{c}\mathbf{m}_{M} \\
(-)\end{array}$ & $\begin{array}{c}k_{F_{2}} \\
\left(m^{2}\right)\end{array}$ & $\begin{array}{c}\alpha_{F} \\
(1 / P a)\end{array}$ & $\begin{array}{l}m_{F} \\
(-)\end{array}$ & $\begin{array}{c}\gamma \\
(-)\end{array}$ \\
\hline tcw11 & $3.74 \mathrm{E}-15$ & $1.01 \mathrm{E}-5$ & 0.388 & $4.24 \mathrm{E}-11$ & $5.27 \mathrm{E}-3$ & 0.633 & 0.587 \\
\hline tcw12 & 5.52E-20 & $3.11 \mathrm{E}-6$ & 0.280 & $9.53 \mathrm{E}-11$ & $1.57 \mathrm{E}-3$ & 0.633 & 0.587 \\
\hline tcw13 & $5.65 E-17$ & $3.26 \mathrm{E}-6$ & 0.259 & $1.32 \mathrm{E}-11$ & $1.24 \mathrm{E}-3$ & 0.633 & 0.587 \\
\hline ptn21 & $9.90 \mathrm{E}-13$ & $1.01 \mathrm{E}-5$ & 0.176 & $1.86 \mathrm{E}-12$ & $1.68 \mathrm{E}-3$ & 0.580 & 0.090 \\
\hline ptn22 & $2.65 \mathrm{E}-12$ & $1.60 \mathrm{E}-4$ & 0.326 & $2.00 \mathrm{E}-11$ & $7.68 \mathrm{E}-4$ & 0.580 & 0.090 \\
\hline ptn23 & 1.23E-13 & $5.58 \mathrm{E}-6$ & 0.397 & $2.60 \mathrm{E}-13$ & $9.23 \mathrm{E}-4$ & 0.610 & 0.090 \\
\hline ptn24 & $7.86 \mathrm{E}-14$ & $1.53 \mathrm{E}-4$ & 0.225 & $4.67 \mathrm{E}-13$ & 3.37E-3 & 0.623 & 0.090 \\
\hline ptn25 & $7.00 \mathrm{E}-14$ & $5.27 \mathrm{E}-5$ & 0.323 & $7.03 E-13$ & $6.33 \mathrm{E}-4$ & 0.644 & 0.090 \\
\hline ptn26 & $2.21 \mathrm{E}-13$ & $2.49 \mathrm{E}-4$ & 0.285 & $4.44 \mathrm{E}-13$ & $2.79 \mathrm{E}-4$ & 0.552 & 0.090 \\
\hline tsw31 & $2.95 \mathrm{E}-17$ & $8.70 \mathrm{E}-5$ & 0.218 & $5.42 \mathrm{E}-12$ & $1.00 \mathrm{E}-4$ & 0.633 & 0.129 \\
\hline tsw32 & $2.23 \mathrm{E}-16$ & $1.14 \mathrm{E}-5$ & 0.290 & $4.72 \mathrm{E}-12$ & $1.00 \mathrm{E}-4$ & 0.633 & 0.600 \\
\hline tsw33 & $6.57 \mathrm{E}-18$ & $6.17 \mathrm{E}-6$ & 0.283 & $5.18 \mathrm{E}-12$ & $1.59 \mathrm{E}-3$ & 0.633 & 0.600 \\
\hline tsw34 & 1.77E-19 & $8.45 \mathrm{E}-6$ & 0.317 & $2.21 \mathrm{E}-12$ & $1.04 \mathrm{E}-4$ & 0.633 & 0.569 \\
\hline tsw35 & $4.48 \mathrm{E}-18$ & $1.08 \mathrm{E}-5$ & 0.216 & $6.08 \mathrm{E}-12$ & $1.02 \mathrm{E}-4$ & 0.633 & 0.569 \\
\hline tsw36 & $2.00 \mathrm{E}-19$ & $8.32 \mathrm{E}-6$ & 0.442 & $8.99 \mathrm{E}-12$ & $7.44 \mathrm{E}-4$ & 0.633 & 0.569 \\
\hline tsw37 & $2.00 \mathrm{E}-19$ & $8.32 \mathrm{E}-6$ & 0.442 & $8.99 \mathrm{E}-12$ & $7.44 \mathrm{E}-4$ & 0.633 & 0.569 \\
\hline tsw38 & $2.00 \mathrm{E}-18$ & $6.23 \mathrm{E}-6$ & 0.286 & $8.10 \mathrm{E}-13$ & $2.12 \mathrm{E}-3$ & 0.633 & 0.569 \\
\hline tswz & $3.50 \mathrm{E}-17$ & $4.61 \mathrm{E}-6$ & 0.059 & $8.10 \mathrm{E}-13$ & $1.50 \mathrm{E}-3$ & 0.633 & 0.370 \\
\hline tswv & $1.49 \mathrm{E}-13$ & $4.86 \mathrm{E}-5$ & 0.293 & $\mathrm{a}$ & $\mathrm{a}$ & $a$ & $\mathrm{a}$ \\
\hline $\operatorname{ch} 1 z$ & $3.50 \mathrm{E}-17$ & $2.12 \mathrm{E}-7$ & 0.349 & $2.50 \mathrm{E}-14$ & $1.40 \mathrm{E}-3$ & 0.633 & 0.370 \\
\hline ch1v & $6.65 \mathrm{E}-13$ & $8.73 \mathrm{E}-5$ & 0.240 & $\mathrm{a}$ & $\mathrm{a}$ & a & $\mathrm{a}$ \\
\hline ch2v & $2.97 \mathrm{E}-11$ & $2.59 \mathrm{E}-4$ & 0.158 & $\mathrm{a}$ & $\mathrm{a}$ & $\mathrm{a}$ & $a$ \\
\hline $\operatorname{ch} 3 v$ & $2.97 \mathrm{E}-11$ & $2.59 \mathrm{E}-4$ & 0.158 & $a$ & $\mathrm{a}$ & $\mathrm{a}$ & $\mathrm{a}$ \\
\hline $\operatorname{ch} 4 v$ & $2.97 \mathrm{E}-11$ & $2.59 \mathrm{E}-4$ & 0.158 & a & $\mathrm{a}$ & $\mathrm{a}$ & $a$ \\
\hline ch5v & $2.97 \mathrm{E}-11$ & $2.59 \mathrm{E}-4$ & 0.158 & $\mathrm{a}$ & $\mathrm{a}$ & $\mathrm{a}$ & $\mathrm{a}$ \\
\hline ch6v & $2.35 \mathrm{E}-13$ & $1.57 \mathrm{E}-5$ & 0.147 & $\mathrm{a}$ & $\mathrm{a}$ & a & $\mathrm{a}$ \\
\hline $\operatorname{ch} 2 z$ & $5.20 \mathrm{E}-18$ & $2.25 \mathrm{E}-6$ & 0.257 & $2.50 \mathrm{E}-14$ & $8.90 \mathrm{E}-4$ & 0.633 & 0.370 \\
\hline $\operatorname{ch} 3 z$ & $5.20 \mathrm{E}-18$ & $2.25 \mathrm{E}-6$ & 0.257 & $2.50 \mathrm{E}-14$ & $8.90 \mathrm{E}-4$ & 0.633 & 0.370 \\
\hline $\operatorname{ch} 4 z$ & $5.20 \mathrm{E}-18$ & $2.25 \mathrm{E}-6$ & 0.257 & $2.50 \mathrm{E}-14$ & $8.90 \mathrm{E}-4$ & 0.633 & 0.370 \\
\hline $\operatorname{ch} 5 z$ & $5.20 \mathrm{E}-18$ & $2.25 \mathrm{E}-6$ & 0.257 & $2.50 \mathrm{E}-14$ & $8.90 \mathrm{E}-4$ & 0.633 & 0.370 \\
\hline $\operatorname{ch} 6 z$ & $8.20 \mathrm{E}-19$ & $1.56 \mathrm{E}-7$ & 0.499 & $2.50 \mathrm{E}-14$ & $1.40 \mathrm{E}-3$ & 0.633 & 0.370 \\
\hline pp4 & $8.77 \mathrm{E}-17$ & $4.49 \mathrm{E}-7$ & 0.474 & $2.50 \mathrm{E}-14$ & $1.83 \mathrm{E}-3$ & 0.633 & 0.370 \\
\hline pp3 & $7.14 \mathrm{E}-14$ & $8.83 \mathrm{E}-6$ & 0.407 & $2.20 \mathrm{E}-13$ & 2.47E-3 & 0.633 & 0.199 \\
\hline pp2 & $1.68 \mathrm{E}-15$ & $2.39 \mathrm{E}-6$ & 0.309 & $2.20 \mathrm{E}-13$ & $3.17 \mathrm{E}-3$ & 0.633 & 0.199 \\
\hline $\mathrm{pp} 1$ & $2.35 \mathrm{E}-15$ & $9.19 \mathrm{E}-7$ & 0.272 & $2.50 \mathrm{E}-14$ & $1.83 \mathrm{E}-3$ & 0.633 & 0.370 \\
\hline bf3 & $4.34 \mathrm{E}-13$ & $1.26 \mathrm{E}-5$ & 0.193 & $2.20 \mathrm{E}-13$ & $2.93 E-3$ & 0.633 & 0.199 \\
\hline bf2 & $8.10 \mathrm{E}-17$ & $1.18 \mathrm{E}-7$ & 0.617 & $2.50 \mathrm{E}-14$ & $8.90 \mathrm{E}-4$ & 0.633 & 0.370 \\
\hline pcM38 & $3.00 \mathrm{E}-19$ & $6.23 \mathrm{E}-6$ & 0.286 & $3.00 \mathrm{E}-18$ & $6.23 \mathrm{E}-6$ & 0.286 & 0.00 \\
\hline pcM39 & $6.20 \mathrm{E}-18$ & $4.61 \mathrm{E}-6$ & 0.059 & $6.20 \mathrm{E}-17$ & $4.61 \mathrm{E}-6$ & 0.059 & 0.00 \\
\hline pcM1z & $9.30 \mathrm{E}-20$ & $2.12 \mathrm{E}-7$ & 0.349 & $9.30 \mathrm{E}-19$ & $2.12 \mathrm{E}-7$ & 0.349 & 0.00 \\
\hline pcM2z & $2.40 \mathrm{E}-18$ & $2.25 \mathrm{E}-6$ & 0.257 & $2.40 \mathrm{E}-17$ & $2.25 \mathrm{E}-6$ & 0.257 & 0.00 \\
\hline pcM5z & $2.40 \mathrm{E}-18$ & $2.25 \mathrm{E}-6$ & 0.257 & $2.40 \mathrm{E}-18$ & $2.25 \mathrm{E}-6$ & 0.257 & 0.00 \\
\hline
\end{tabular}




\begin{tabular}{|l|l|l|l|l|l|l|l|}
\hline pcM6z & $1.10 \mathrm{E}-19$ & $1.56 \mathrm{E}-7$ & 0.499 & $1.10 \mathrm{E}-19$ & $1.56 \mathrm{E}-7$ & 0.499 & 0.00 \\
\hline pcM4p & $7.70 \mathrm{E}-19$ & $4.49 \mathrm{E}-7$ & 0.474 & $7.70 \mathrm{E}-19$ & $4.49 \mathrm{E}-7$ & 0.474 & 0.00 \\
\hline
\end{tabular}

a Model layers do not include fractures.

Table $4 \quad$ Eight simulation scenarios for sensitivity and uncertainty analyses of Unsaturated Zone Flow Model parameters: Parameter sets and their variations, as well as the base-case simulation scenario (glaq_mA)

\begin{tabular}{|c|c|}
\hline $\begin{array}{l}\text { Simulation/ } \\
\text { Designation }\end{array}$ & $\begin{array}{c}\text { Parameter Set/ } \\
\text { Variation }\end{array}$ \\
\hline 1: glaq+kM & Table 3 with $k_{M}+\sigma_{k_{m}}{ }^{*}$ \\
\hline 2: glaq-kM & Table 3 with $k_{M}-\sigma_{k_{M}}$ \\
\hline 3: glaq+aM & Table 3 with $\alpha_{M}+\sigma_{\alpha_{M}}$ \\
\hline 4: glaq-aM & Table 3 with $\alpha_{M}-\sigma_{\alpha_{M}}$ \\
\hline 5: glaq+kF & Table 3 with $k_{F}+\sigma_{k_{F}}$ \\
\hline 6: glaq-kF & Table 3 with $k_{F}-\sigma_{k_{F}}$ \\
\hline 7: glaq $+\mathrm{aF}$ & Table 3 with $\alpha_{F}+\sigma_{\alpha_{F}}$ \\
\hline 8: glaq-aF & Table 3 with $\alpha_{F}-\sigma_{\alpha_{F}}$ \\
\hline qlaq_mA & Table 3 (base-case scenario) \\
\hline
\end{tabular}


Table 5. Comparison of the water flux through matrix, fractures and faults as a percentage of the total flux over the entire model domain and within the repository footprint at three different horizons for the eight simulations as well as the base case results.

\begin{tabular}{|l|l|l|l|l|l|l|c|}
\hline \multirow{2}{*}{$\begin{array}{c}\text { Simulation } \\
\text { Designation }\end{array}$} & \multicolumn{3}{|c|}{$\begin{array}{c}\text { Flux at TCw/PTn Interface over } \\
\text { Entire Model Domain (\%) }\end{array}$} & \multicolumn{3}{c|}{ Flux at TCw/PTn Interface within Repository } \\
\cline { 2 - 8 } & Fracture & Matrix & Fault & Fracture & Matrix & Fault & $\begin{array}{c}\text { Total Flow } \\
\text { Rate (kg/s) }\end{array}$ \\
\hline glaq_mA & 95.1 & 1.1 & 3.8 & 98.6 & 0.0 & 1.4 & 3.1 \\
\hline glaq+kM & 94.4 & 1.6 & 3.9 & 98.5 & 0.1 & 1.5 & 3.1 \\
\hline glaq-kM & 95.3 & 1.0 & 3.8 & 98.6 & 0.0 & 1.4 & 3.1 \\
\hline glaq+aM & 95.3 & 1.0 & 3.8 & 98.6 & 0.0 & 1.4 & 3.1 \\
\hline glaq-aM & 95.0 & 1.3 & 3.8 & 98.6 & 0.0 & 1.4 & 3.1 \\
\hline glaq+kF & 95.1 & 1.1 & 3.8 & 98.6 & 0.0 & 1.4 & 3.1 \\
\hline glaq-kF & 95.1 & 1.1 & 3.8 & 98.6 & 0.0 & 1.4 & 3.1 \\
\hline glaq+aF & 95.1 & 1.1 & 3.8 & 98.6 & 0.0 & 1.4 & 3.1 \\
\hline glaq-aF & 95.2 & 1.1 & 3.8 & 98.6 & 0.0 & 1.4 & 3.1 \\
\hline
\end{tabular}

(a) Flux Distribution at the TCw/PTn Interface

\begin{tabular}{|c|c|c|c|c|c|c|c|}
\hline \multirow[b]{2}{*}{$\begin{array}{c}\text { Simulation } \\
\text { Designation }\end{array}$} & \multicolumn{3}{|c|}{$\begin{array}{l}\text { Flux at Repository Level over } \\
\text { Entire Model Domain (\%) }\end{array}$} & \multicolumn{4}{|c|}{$\begin{array}{l}\text { Flux at Repository Horizon within Repository } \\
\text { Footprint (\%) }\end{array}$} \\
\hline & Fracture & Matrix & Fault & Fracture & Matrix & Fault & $\begin{array}{l}\text { Total Flow } \\
\text { Rate }(\mathbf{k g} / \mathbf{s})\end{array}$ \\
\hline glaq_mA & 70.2 & 5.5 & 24.3 & 98.5 & 0.2 & 1.4 & 3.1 \\
\hline glaq+kM & 60.5 & 16.8 & 22.7 & 87.9 & 9.5 & 2.6 & 1.2 \\
\hline glaq-kM & 69.3 & 5.1 & 25.7 & 98.6 & 0.0 & 1.4 & 3.1 \\
\hline glaq $+a M$ & 69.3 & 5.4 & 25.4 & 98.5 & 0.0 & 1.5 & 3.1 \\
\hline glaq-aM & 69.3 & 8.0 & 22.7 & 97.4 & 0.8 & 1.8 & 2.8 \\
\hline glaq+kF & 70.1 & 5.1 & 24.8 & 98.4 & 0.1 & 1.5 & 3.1 \\
\hline glaq-kF & 70.9 & 5.8 & 23.3 & 98.6 & 0.3 & 1.1 & 3.1 \\
\hline glaq $+\mathrm{aF}$ & 70.1 & 6.3 & 23.6 & 98.4 & 0.3 & 1.3 & 3.1 \\
\hline glaq-aF & 69.2 & 5.1 & 25.7 & 97.8 & 0.1 & 2.1 & 3.1 \\
\hline
\end{tabular}

(b) Flux Distribution at the Repository Level

\begin{tabular}{|l|l|l|l|l|l|l|c|}
\hline \multirow{2}{*}{$\begin{array}{c}\text { Simulation } \\
\text { Designation }\end{array}$} & \multicolumn{3}{|c|}{$\begin{array}{c}\text { Flux at Water Table over Entire } \\
\text { Model Domain (\%) }\end{array}$} & \multicolumn{4}{c|}{ Flux at Water Table within Repository } \\
\cline { 2 - 8 } & Fracture & Matrix & Fault & Fracture & Matrix & Fault & $\begin{array}{c}\text { Total Flow } \\
\text { Rate (kg/s) }\end{array}$ \\
\cline { 2 - 8 } glaq_mA & 11.5 & 27.0 & 61.6 & 7.8 & 42.3 & 49.9 & 2.2 \\
\hline glaq+kM & 11.7 & 32.5 & 55.8 & 6.2 & 55.9 & 37.9 & 1.8 \\
\hline glaq-kM & 21.1 & 15.0 & 63.8 & 21.6 & 29.3 & 49.2 & 2.2 \\
\hline glaq+aM & 12.6 & 24.4 & 63.0 & 9.4 & 41.2 & 49.5 & 2.1 \\
\hline glaq-aM & 10.8 & 28.6 & 60.6 & 7.1 & 46.0 & 46.9 & 2.2 \\
\hline glaq+kF & 18.2 & 20.0 & 61.8 & 23.7 & 26.3 & 50.0 & 2.2 \\
\hline glaq-kF & 9.6 & 29.5 & 61.0 & 6.1 & 45.0 & 48.9 & 2.1 \\
\hline glaq+aF & 10.2 & 26.5 & 63.2 & 6.3 & 41.3 & 52.3 & 2.2 \\
\hline glaq-aF & 15.0 & 27.9 & 57.1 & 11.9 & 42.2 & 46.0 & 2.2 \\
\hline
\end{tabular}

(c) Flux Distribution at the Water Table 


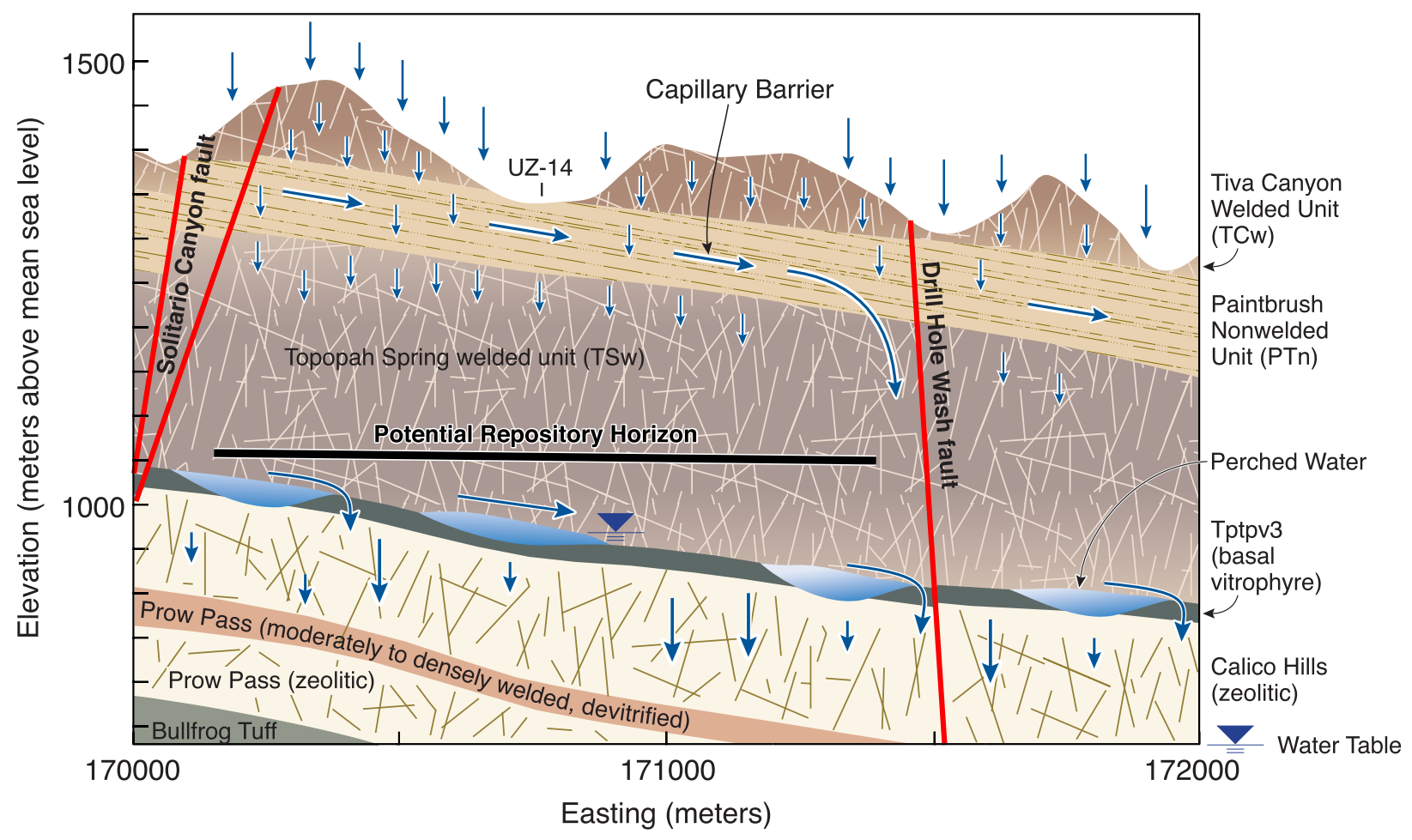

UZ03-002

Figure 1. Schematic showing the conceptualized flow processes and effects of capillary barriers, major faults, and perched-water zones within a typical east-west cross section of the UZ flow model domain 

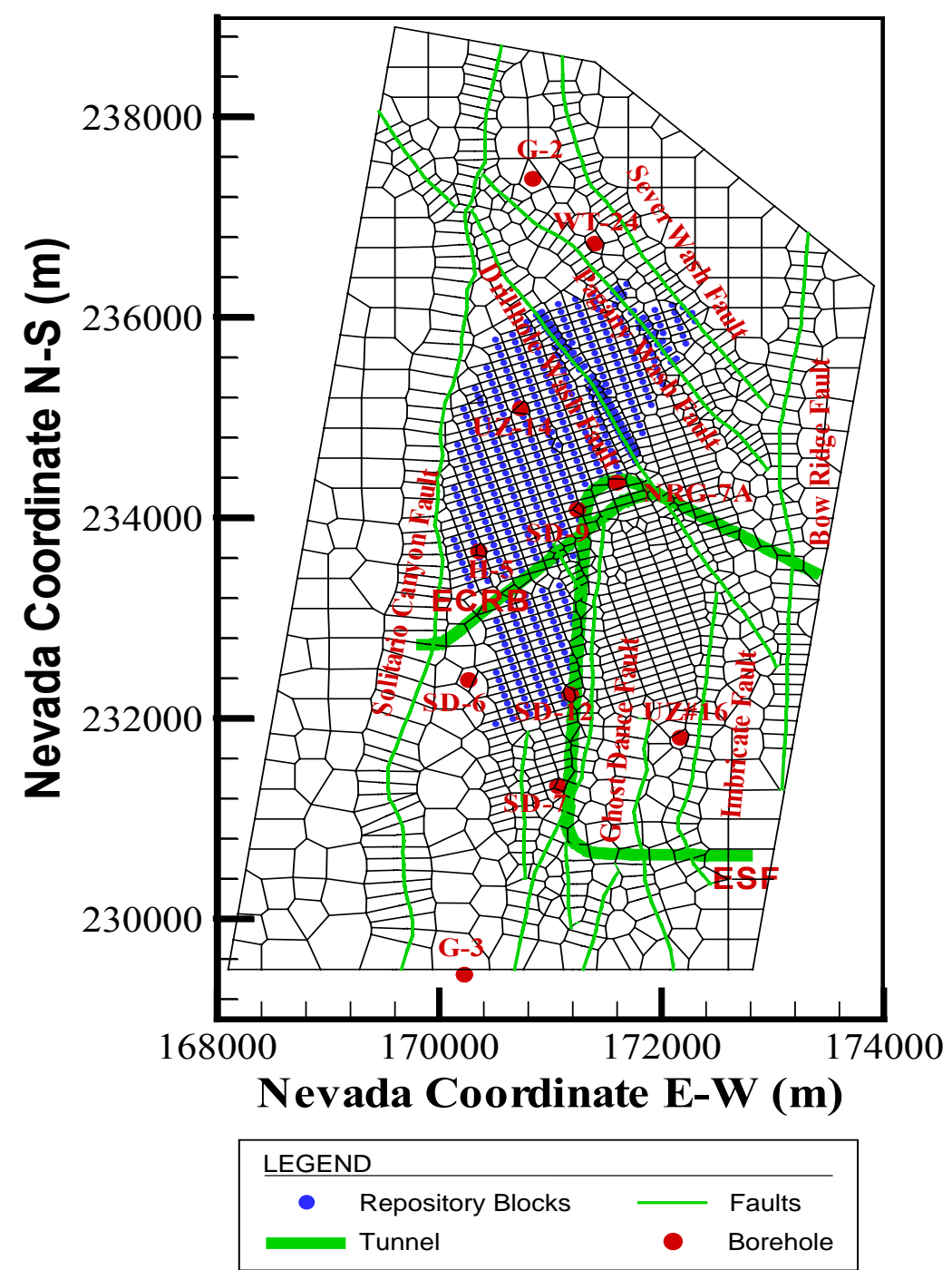

Figure 2. Plan view of the three-dimensional UZ Flow Model grid, showing the model domain, faults incorporated, repository layout, and borehole locations 


\section{Glacial Transition Infiltration (Mean)}

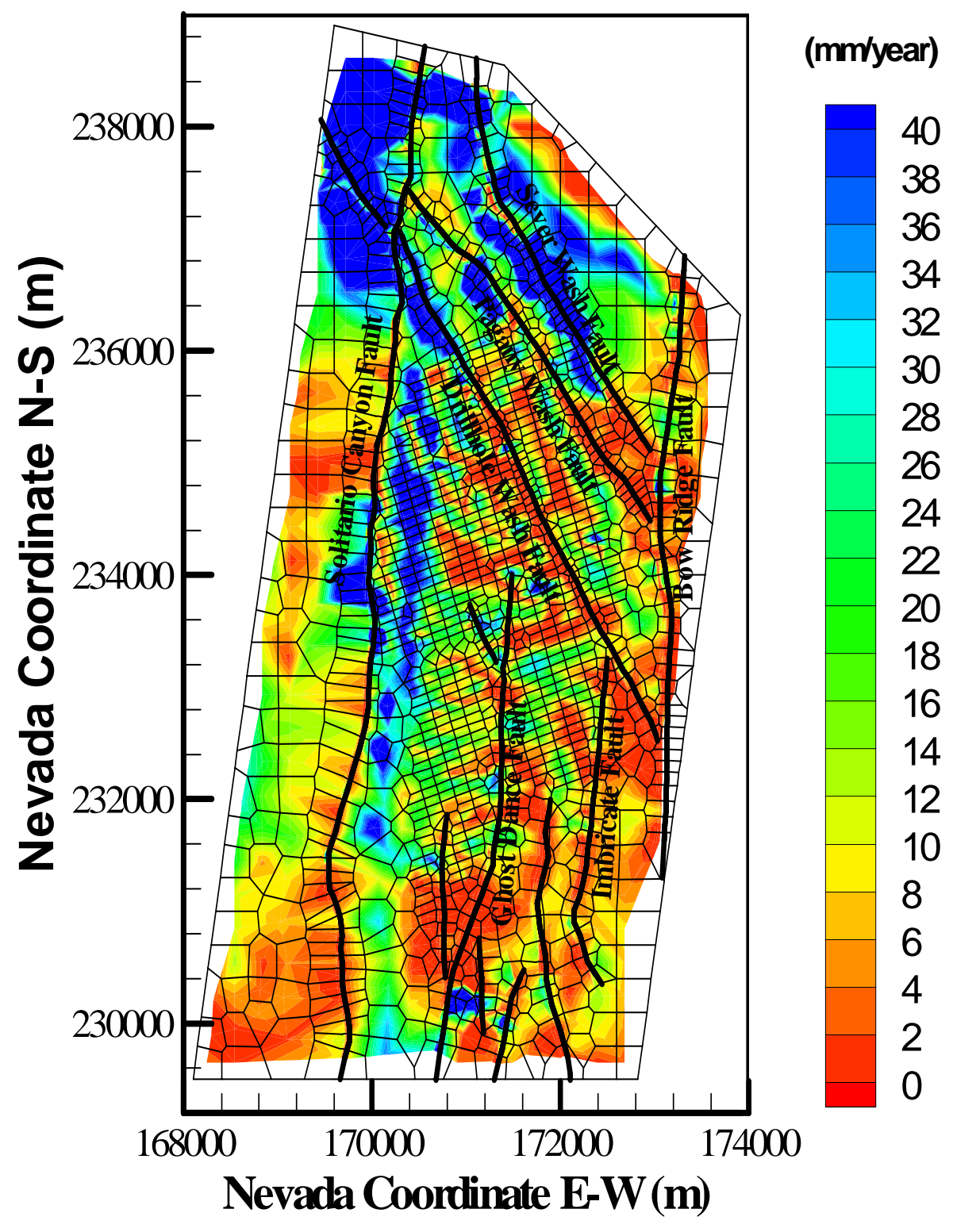

Figure 3. Plan view of net infiltration distributed over the three-dimensional UZ model grid for the glacial transition mean infiltration scenario 


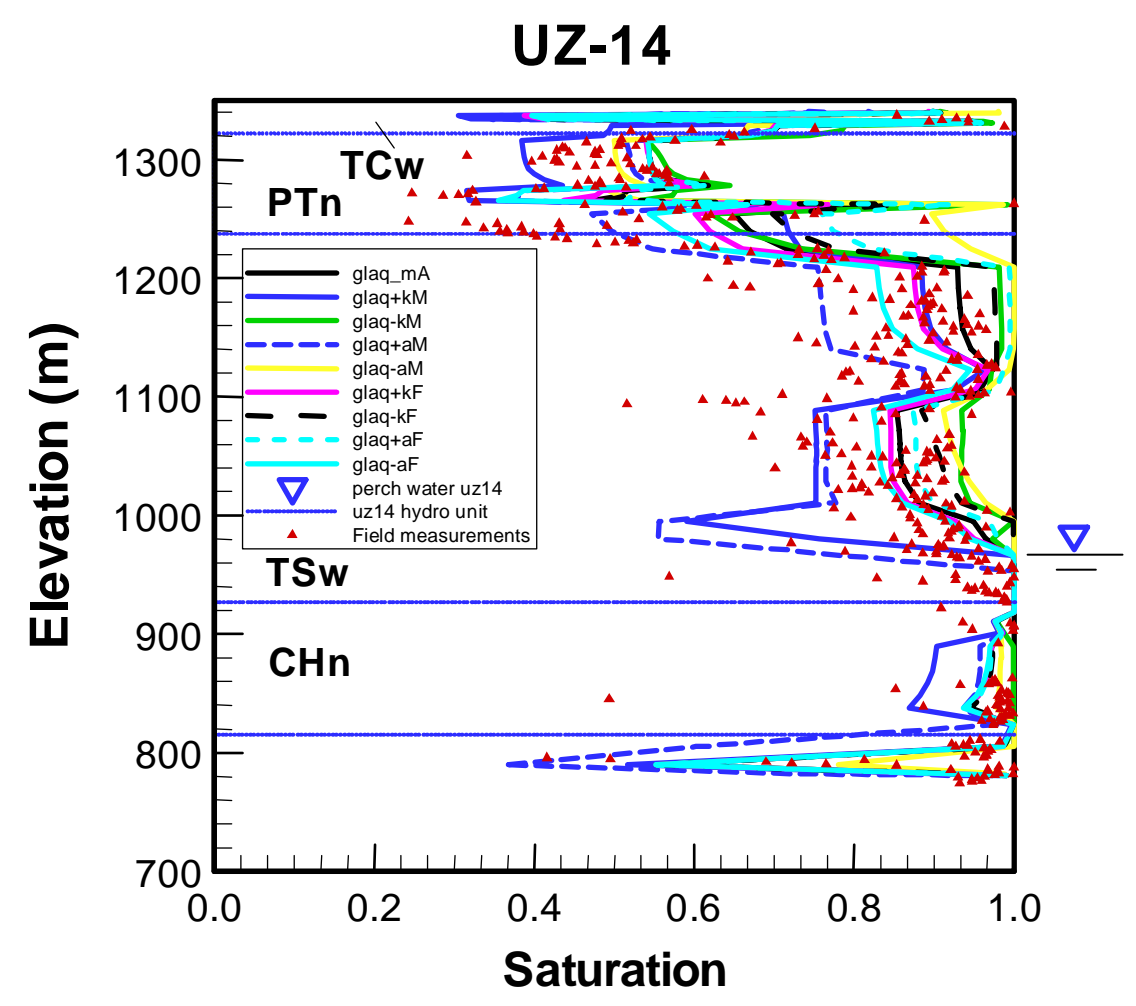

Figure 4. Simulated matrix liquid saturations at borehole UZ-14 from the results of the eight simulation scenarios as well as the base-case simulation (glaq_mA) 


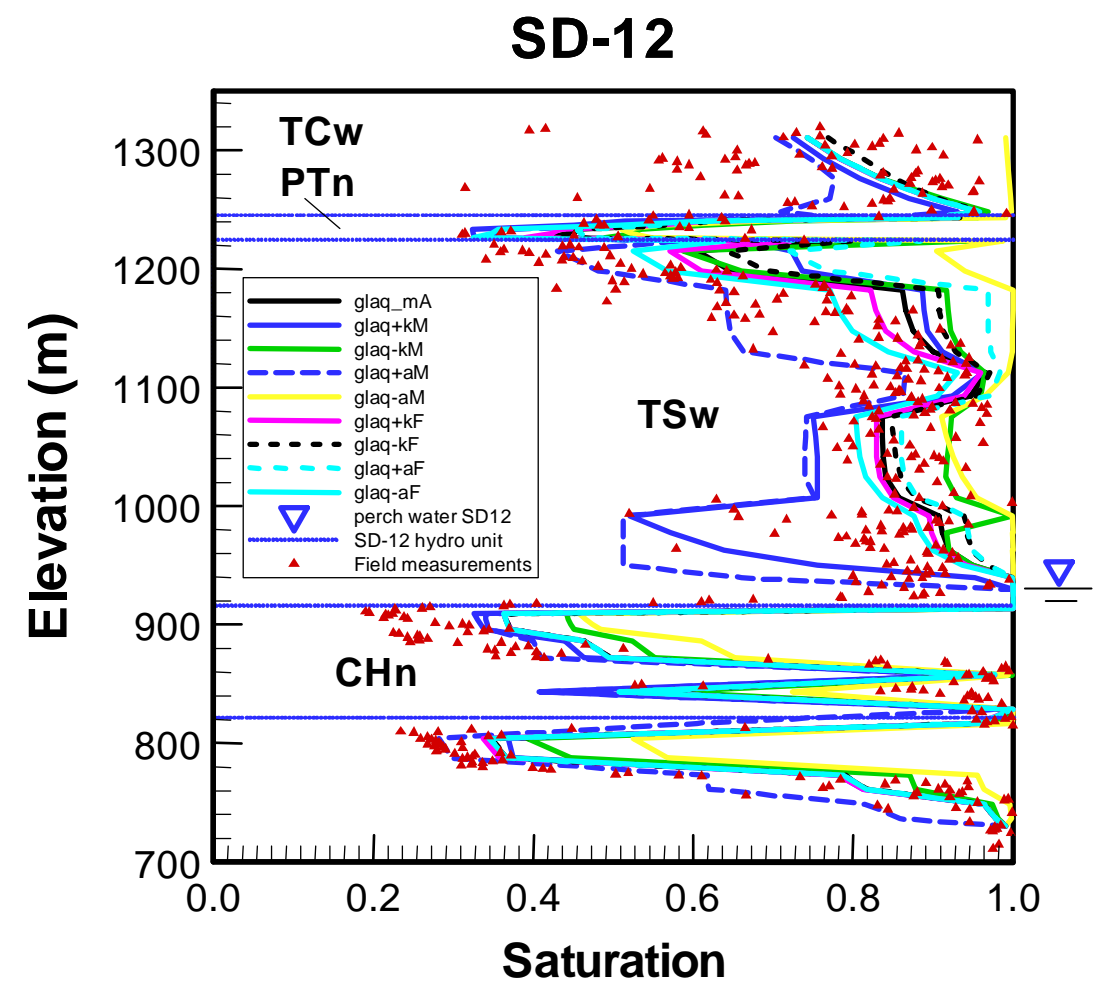

Figure 5. Simulated matrix liquid saturations at borehole SD-12 from the results of the eight simulation scenarios as well as the base-case simulation (glaq_mA) 
SD-12

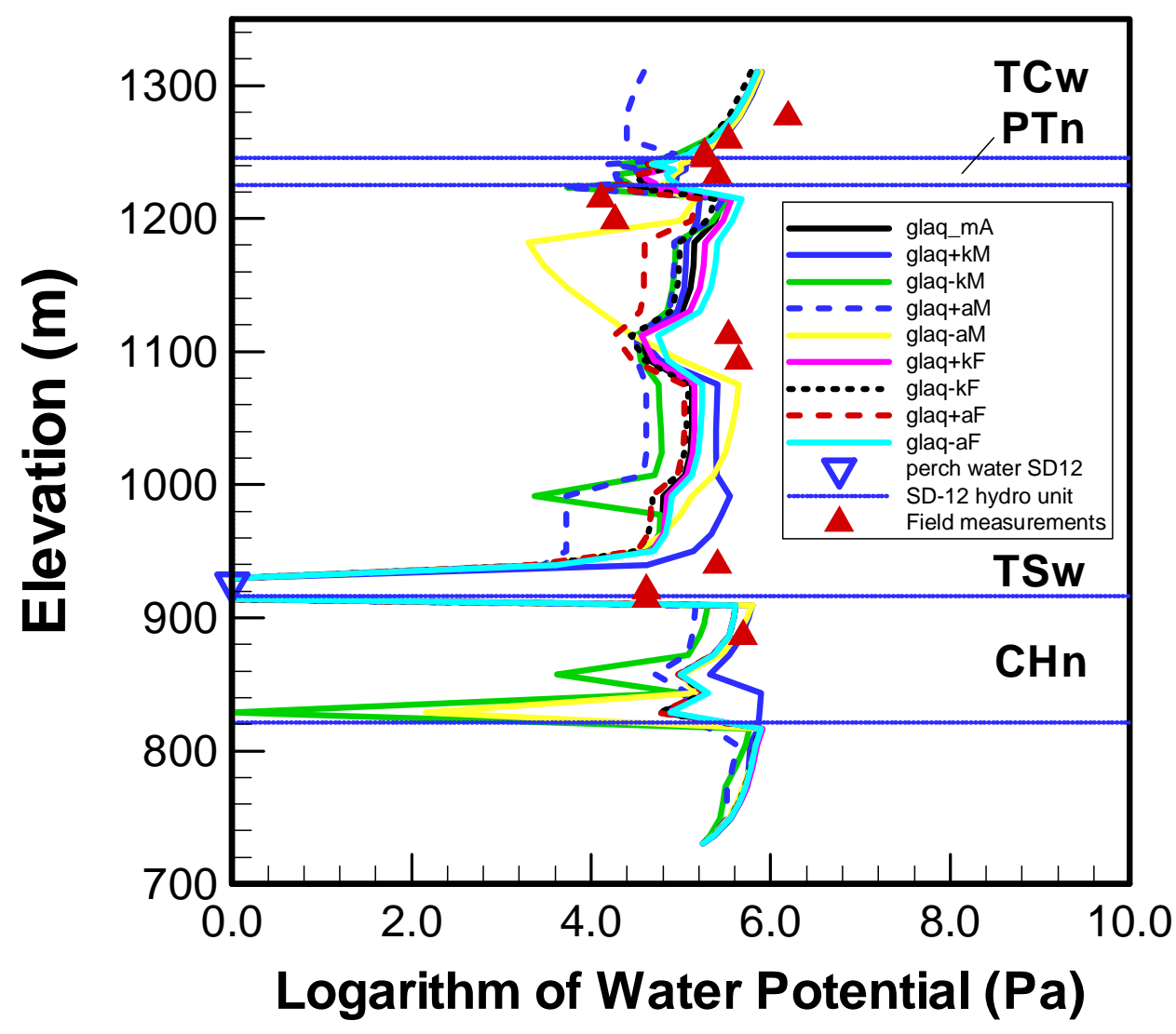

Figure 6. Simulated water potentials at borehole SD-12 from the results of the eight simulation scenarios as well as the base-case simulation (glaq_mA) 


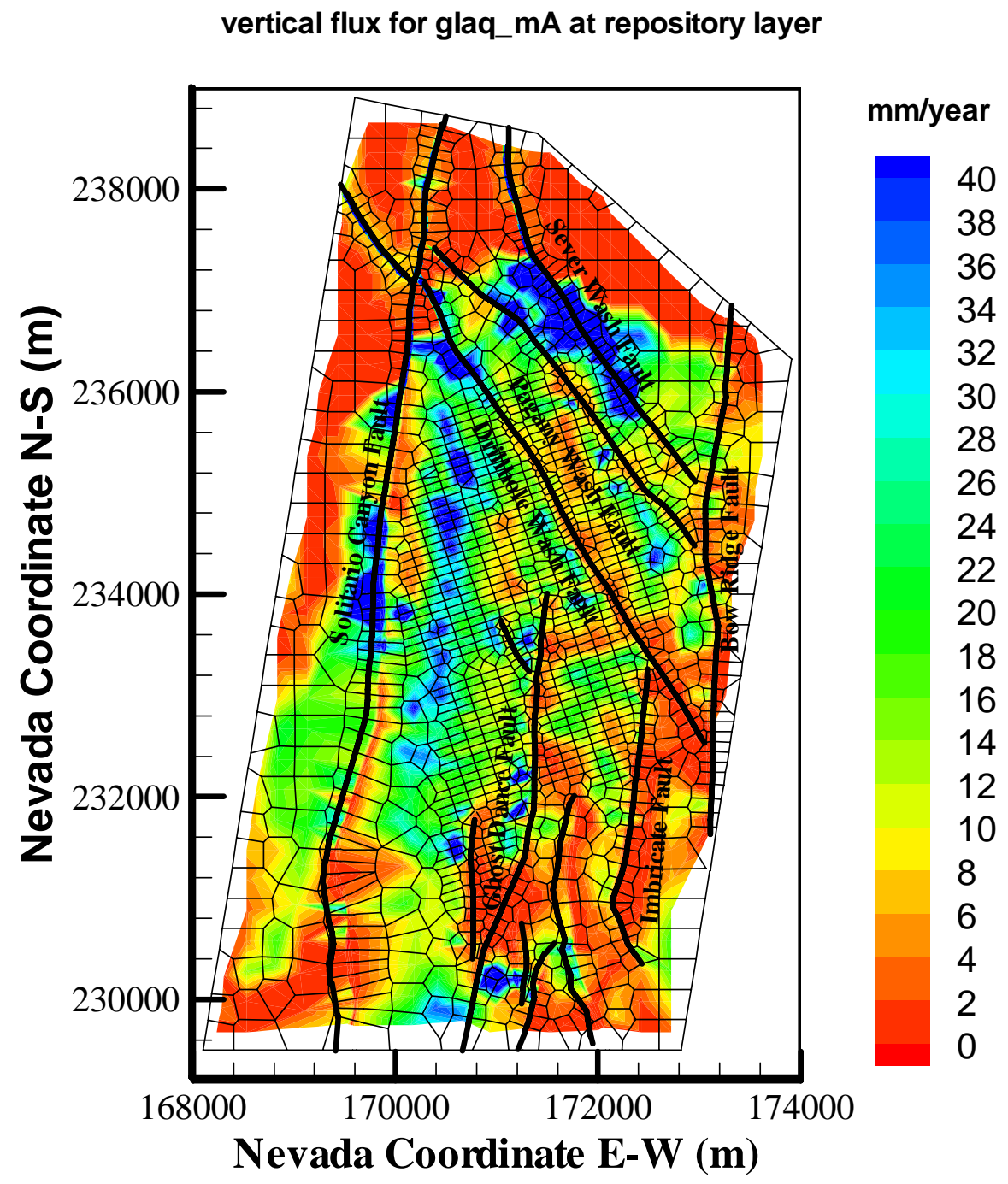

Figure 7. Simulated percolation fluxes at the repository horizon under the glacial-transition mean infiltration scenario using the results of the base-case simulation (glaq_mA) 
Vertical flux at repository layer (glaq+kM)

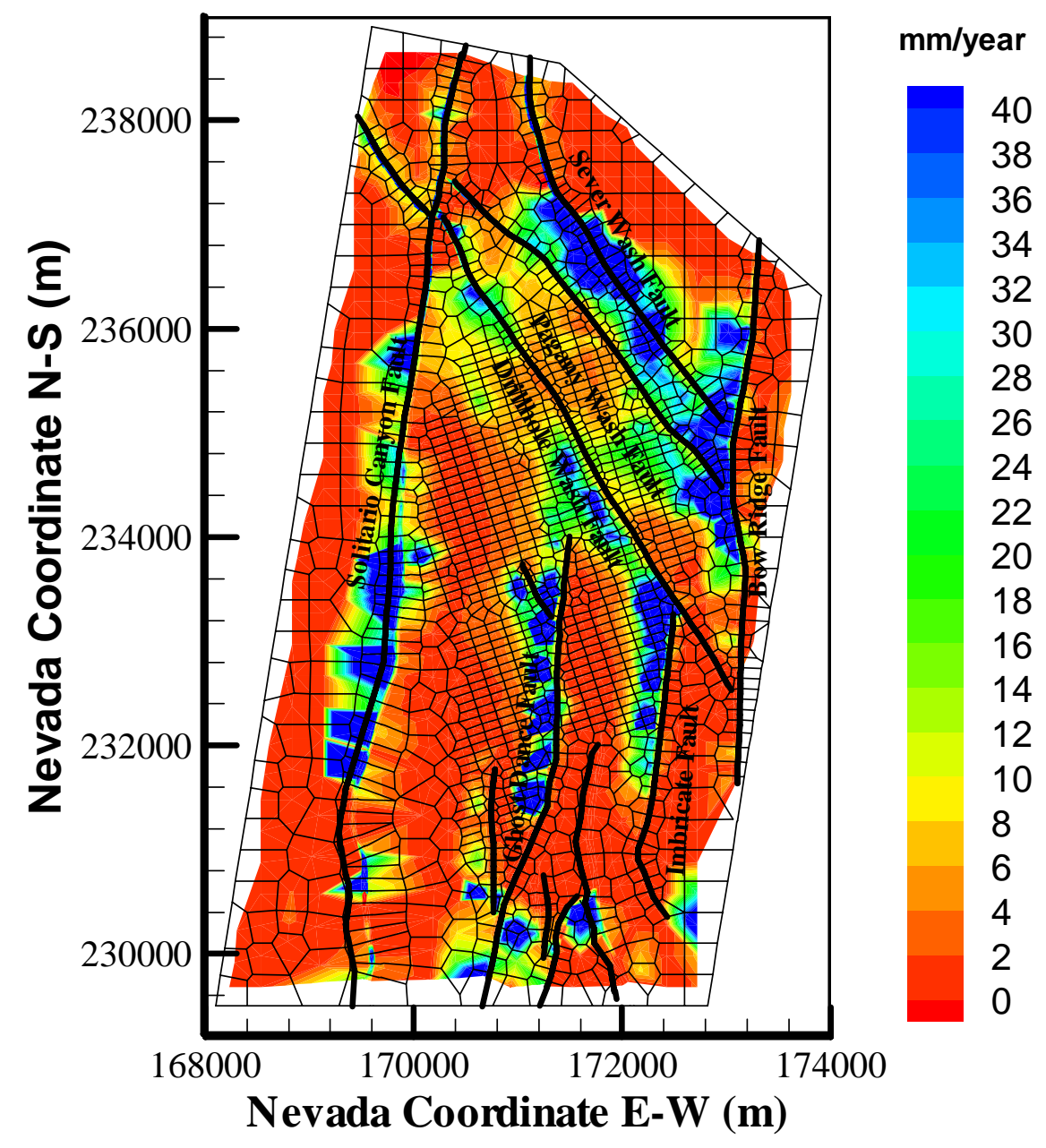

Figure 8. Simulated percolation fluxes at the repository horizon using the base-case parameter set with increase in matrix permeability by one standard deviation using the results of simulation: glaq $+\mathrm{kM}$ 
Vertical flux at repository layer (glaq-aM)

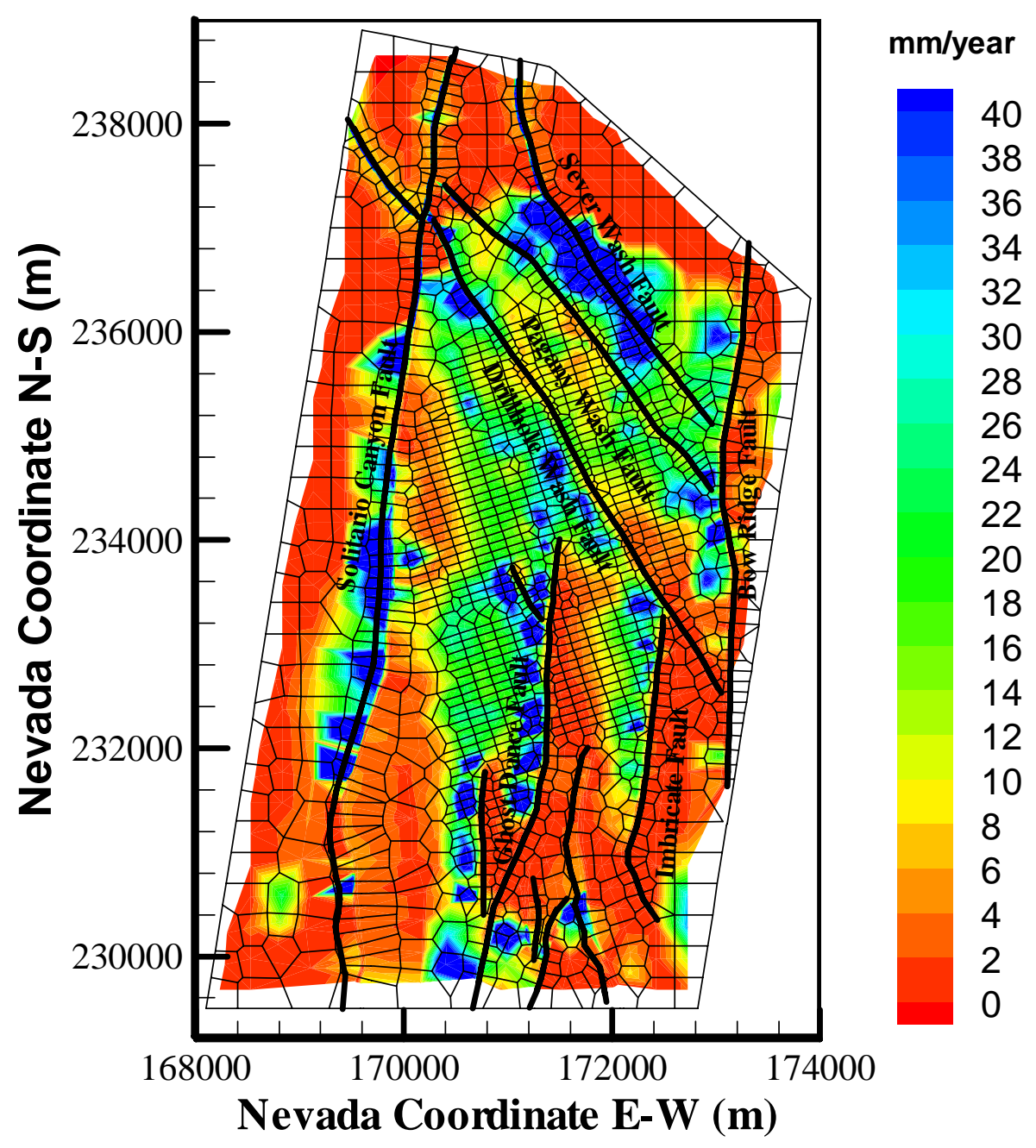

Figure 9. Simulated percolation fluxes at the repository horizon using the base-case parameter set with decrease in matrix van Genuchten parameter $\alpha$ by one standard deviation using the results of simulation: glaq-aM 
vertical flux for glaq_mA at bottom boundary

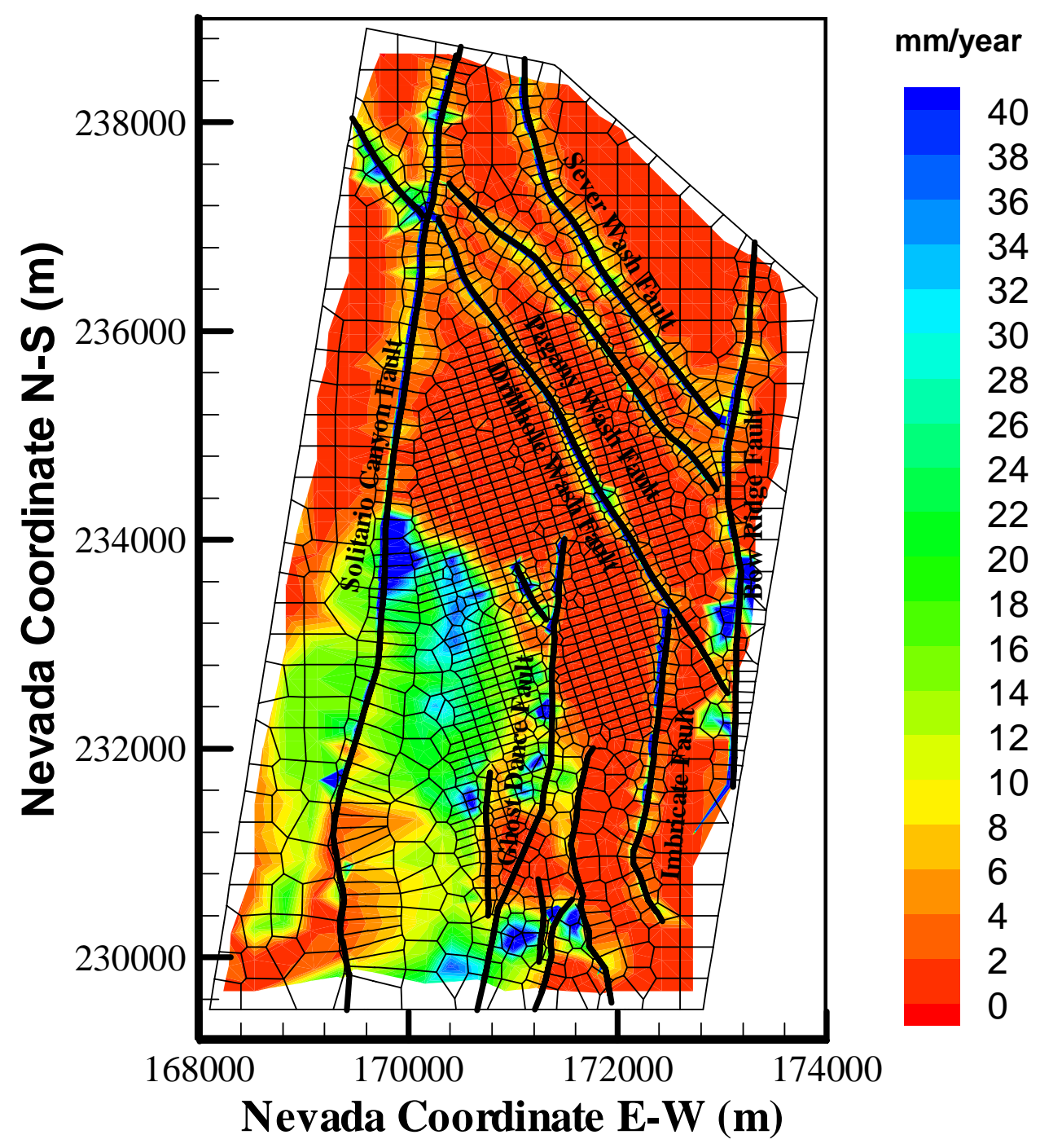

Figure 10. Simulated percolation fluxes at the water table under the glacial transition mean infiltration scenario using the results of the base-case simulation: glaq_mA 


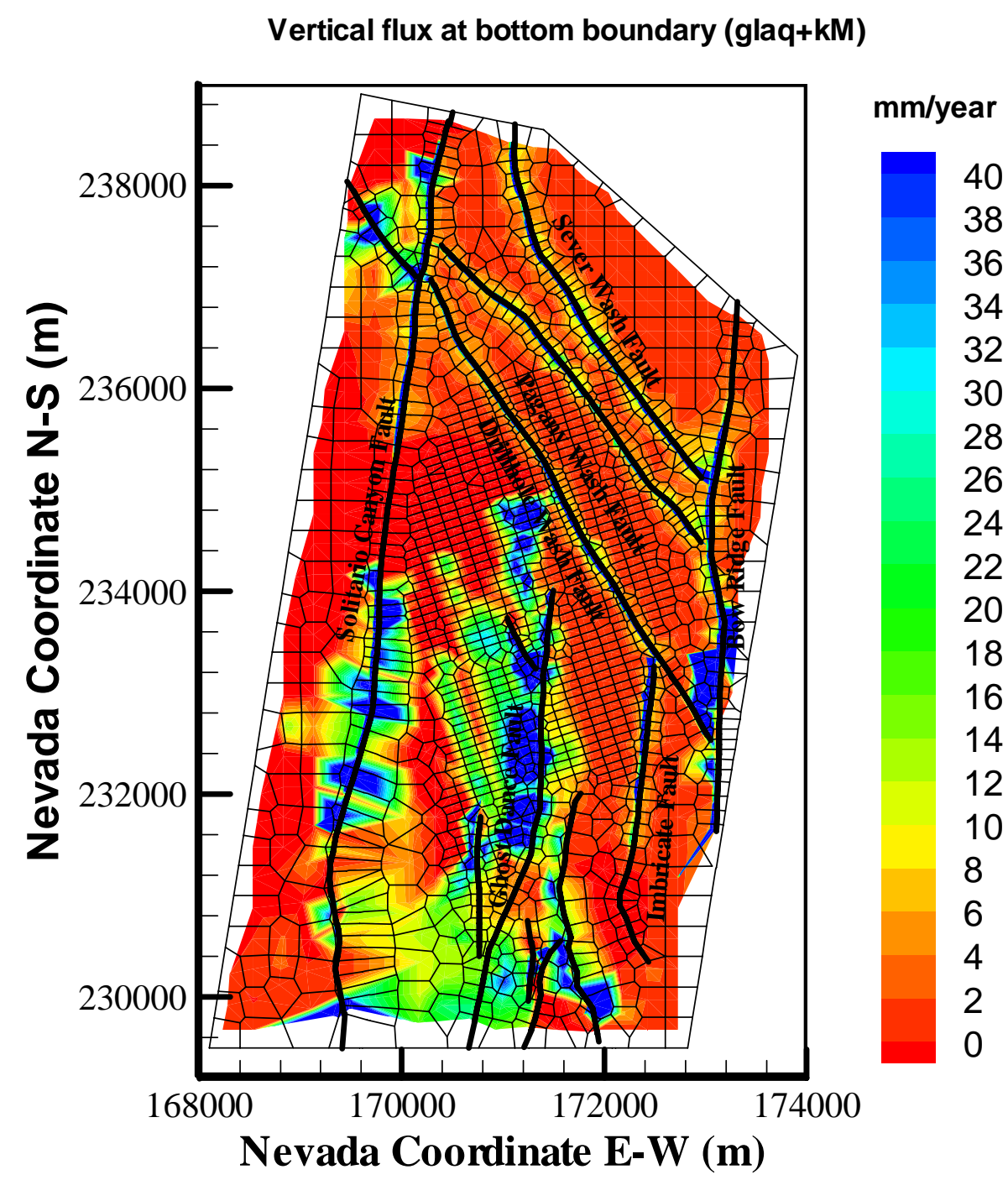

Figure 11 Simulated percolation fluxes at the water table using the base-case parameter set with increase in matrix permeability by one standard deviation using the results of simulation: glaq $+\mathrm{kM}$ 


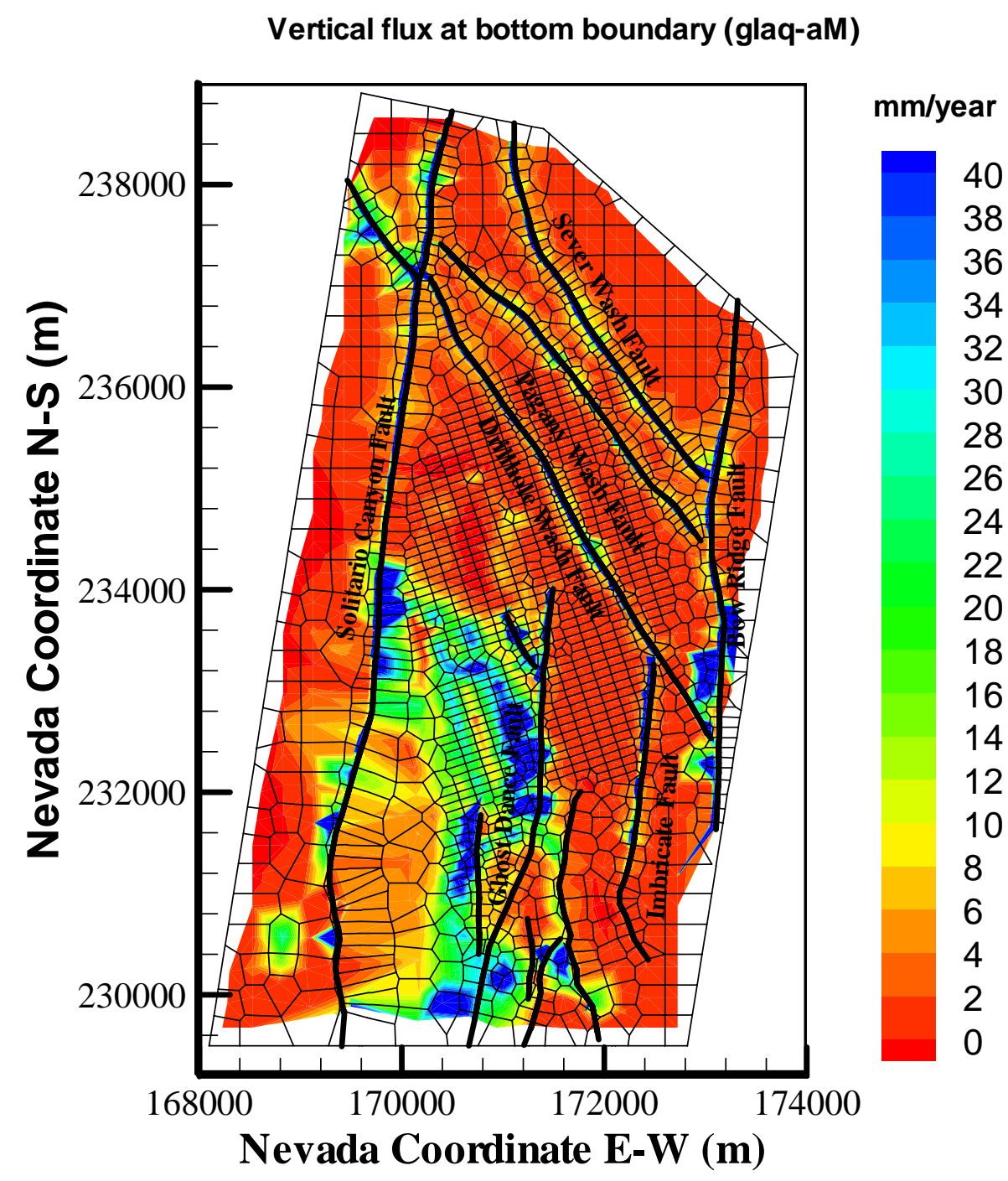

Figure 6-12. Simulated percolation fluxes at the water table using the base-case parameter set with decrease in matrix van Genuchten parameter $\alpha$ by one standard deviation using the results of simulation: glaq-aM 


\section{Normalized Flux Distribution at Repository Footprint}

(glacial transition, mean infiltration, Base case)

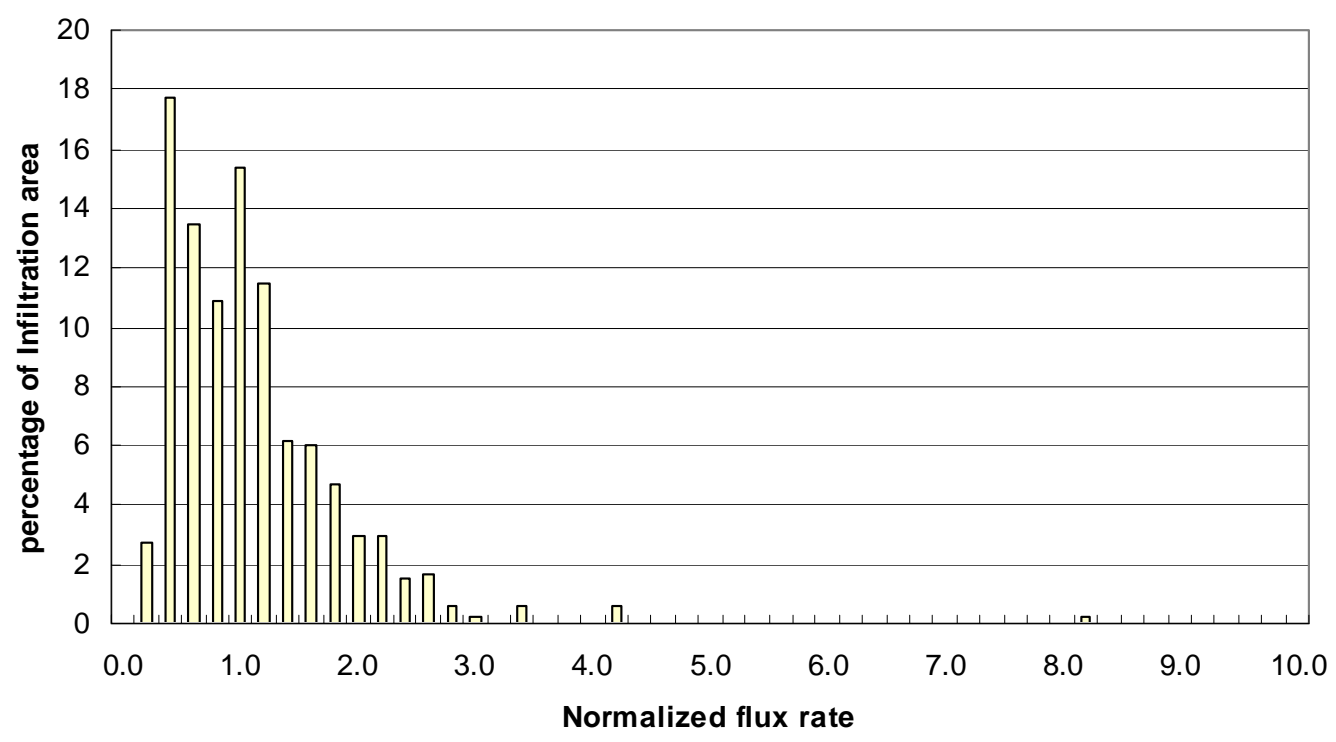

Figure 13 Area frequency and distribution of simulated percolation fluxes within the repository domain normalized to the mean glacial transition infiltration rate (17.02 mm/yr) of the base-case simulation (glaq_mA) 
Normalized Flux Distribution at Repository Footprint

(+kM)

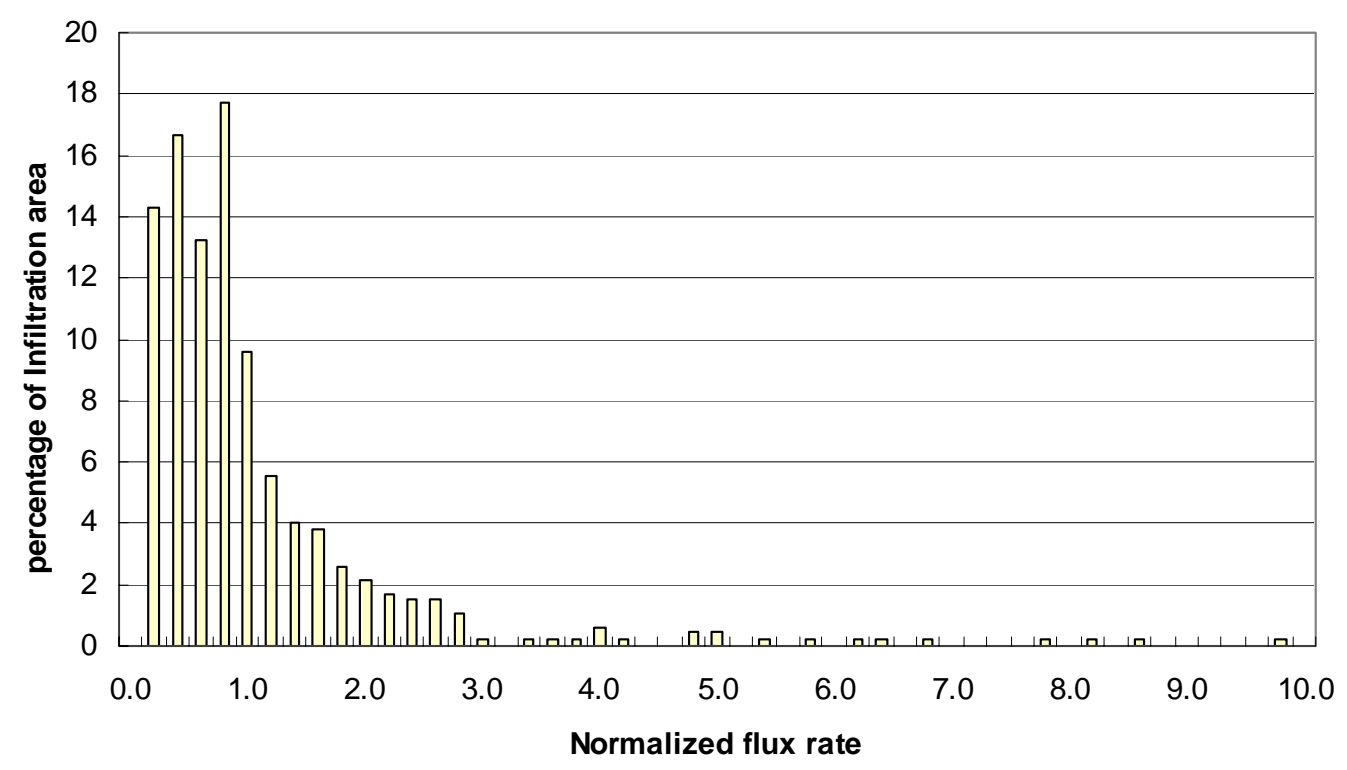

Normalized Flux Distribution at Repository Footprint

(-kM)

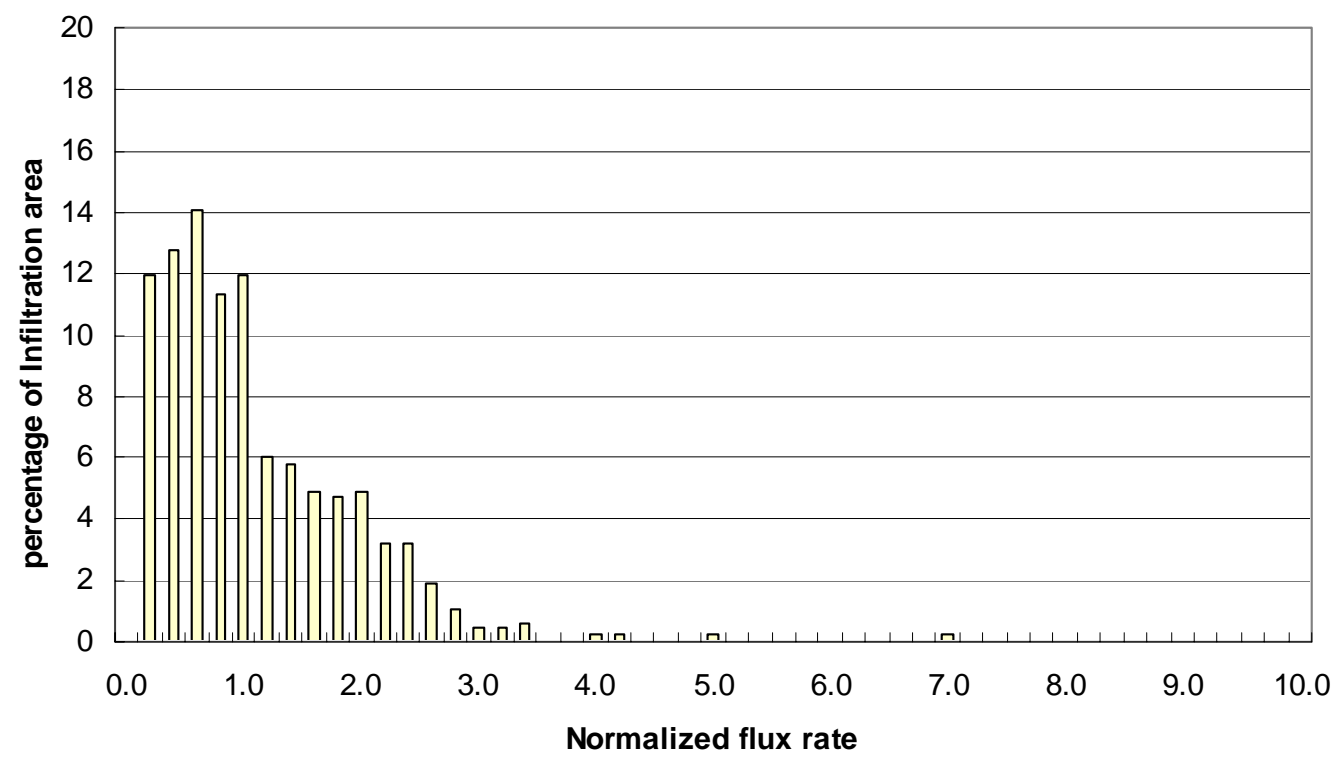

Figure 14 Area frequency and distribution of simulated percolation fluxes within the repository domain normalized to the mean glacial transition infiltration rate $(17.02 \mathrm{~mm} / \mathrm{yr})$, simulated using the base-case parameter set with variations in matrix permeability (glaq $+\mathrm{kM}$ and glaq-kM) 

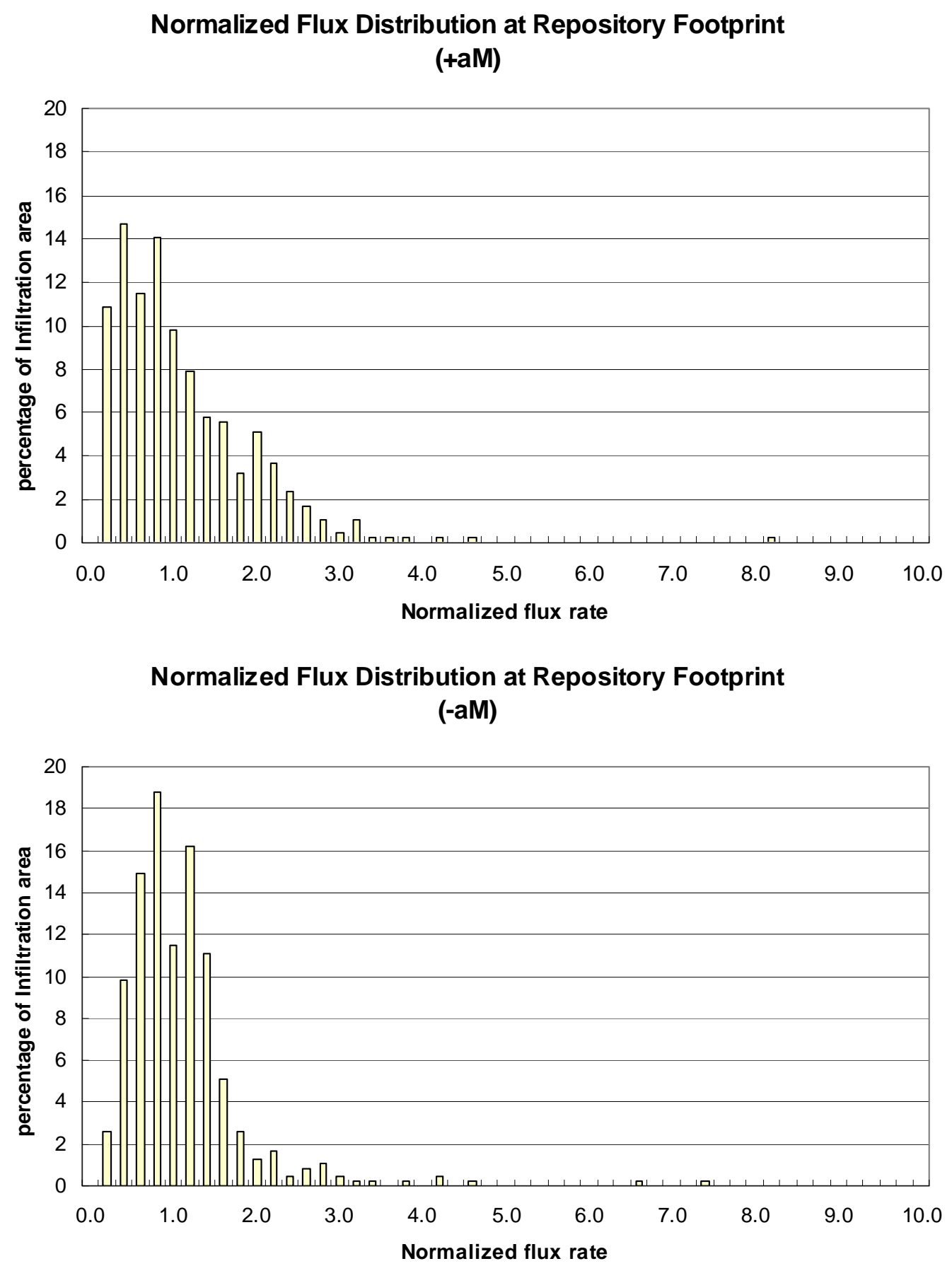

Figure 15 Area frequency and distribution of simulated percolation fluxes within the repository domain normalized to the mean glacial transition infiltration rate $(17.02 \mathrm{~mm} / \mathrm{yr})$, simulated using the base-case parameter set with variations in matrix van Genuchten parameter $\alpha$ (glaq $+\mathrm{aM}$ and glaq-aM) 


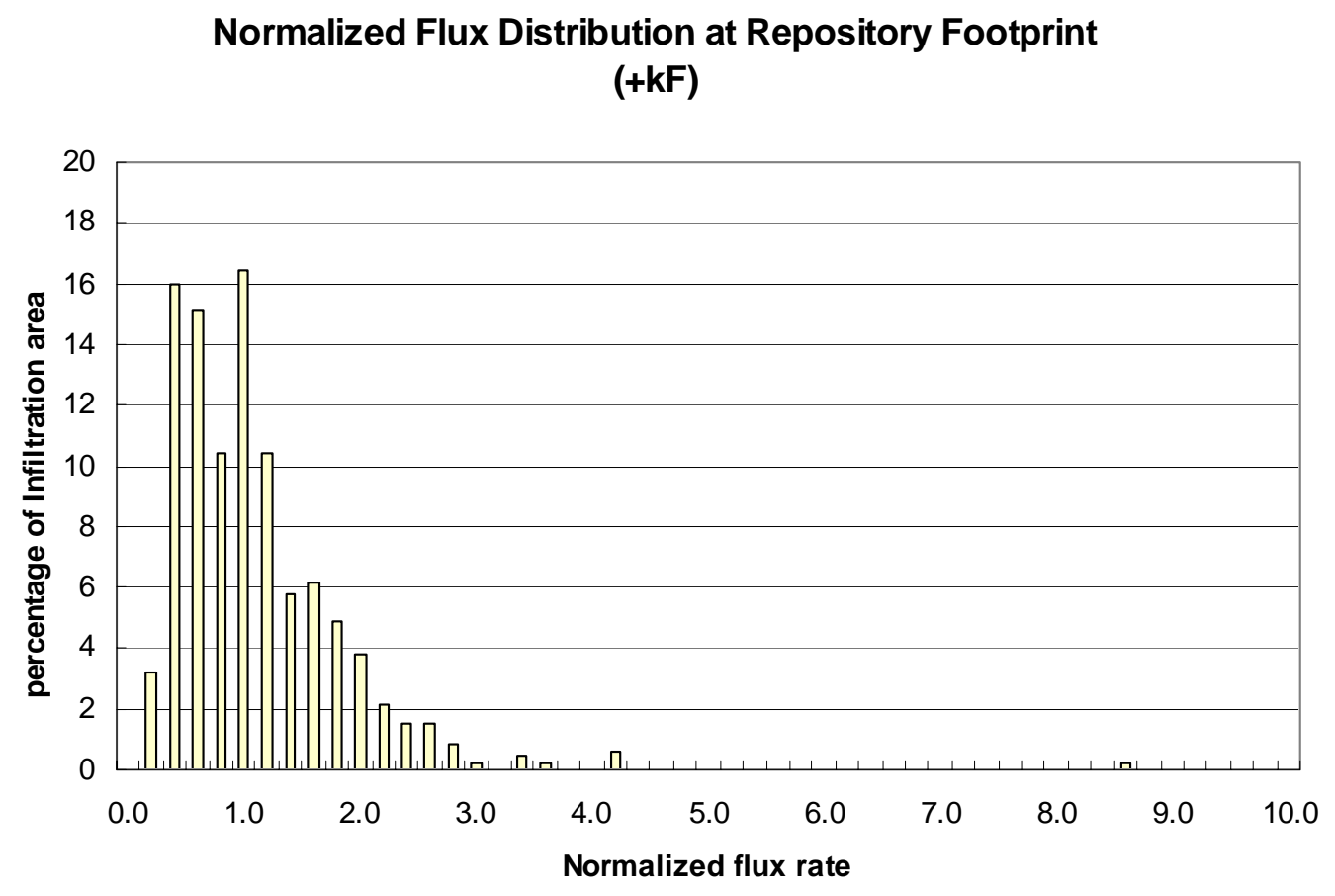

Normalized Flux Distribution at Repository Footprint

(-kF)

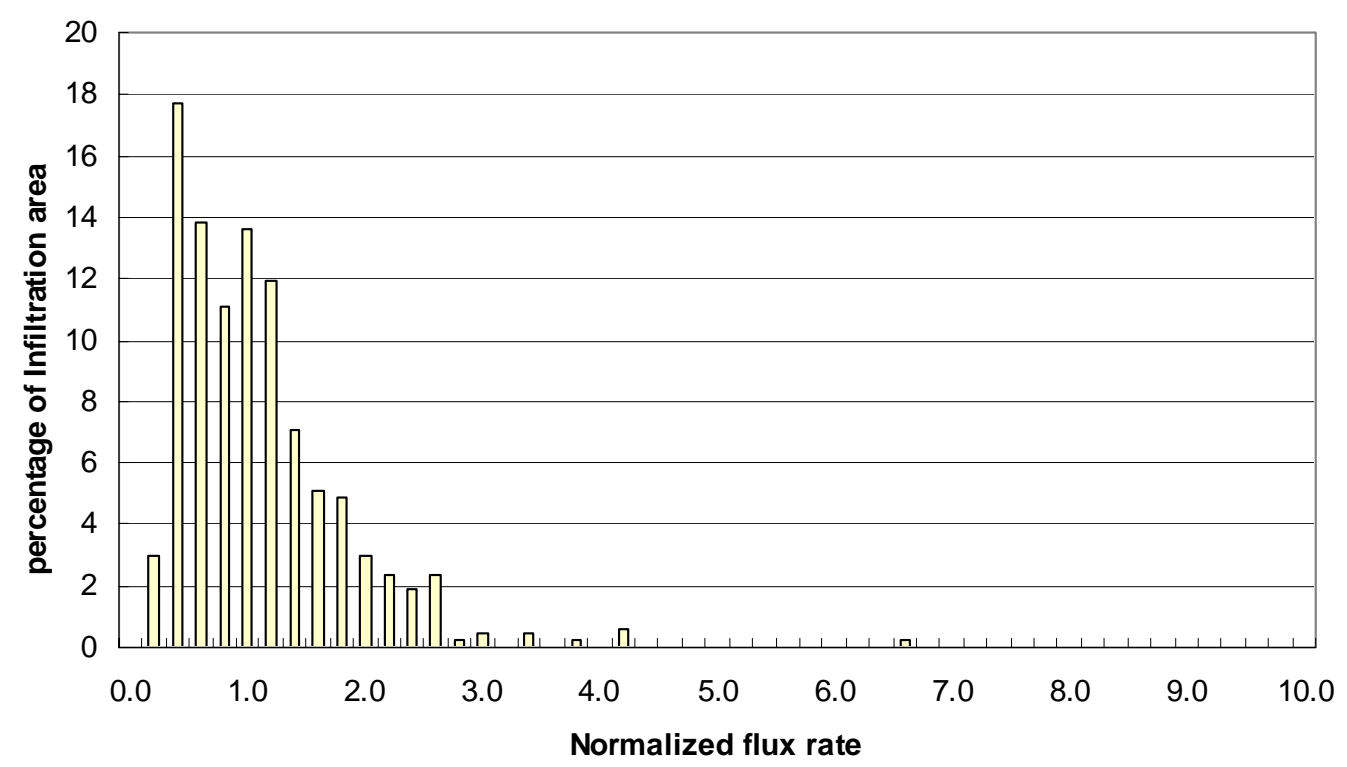

Figure 16 Area frequency and distribution of simulated percolation fluxes within the repository domain normalized to the mean glacial transition infiltration rate $(17.02 \mathrm{~mm} / \mathrm{yr})$, simulated using the base-case parameter set with variations in fracture permeability (glaq $+\mathrm{kF}$ and glaq-kF) 
Normalized Flux Distribution at Repository Footprint

$(+\mathrm{aF})$

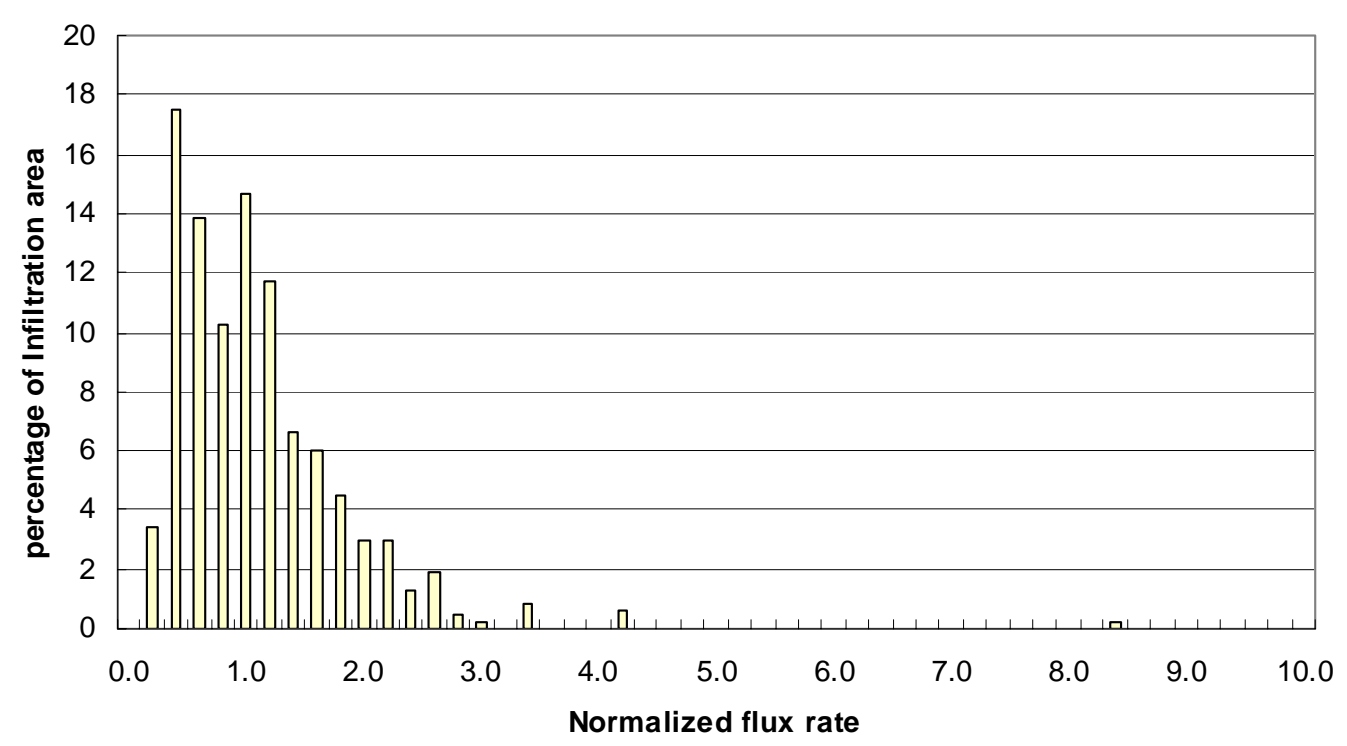

Normalized Flux Distribution at Repository Footprint

$(-\mathrm{aF})$

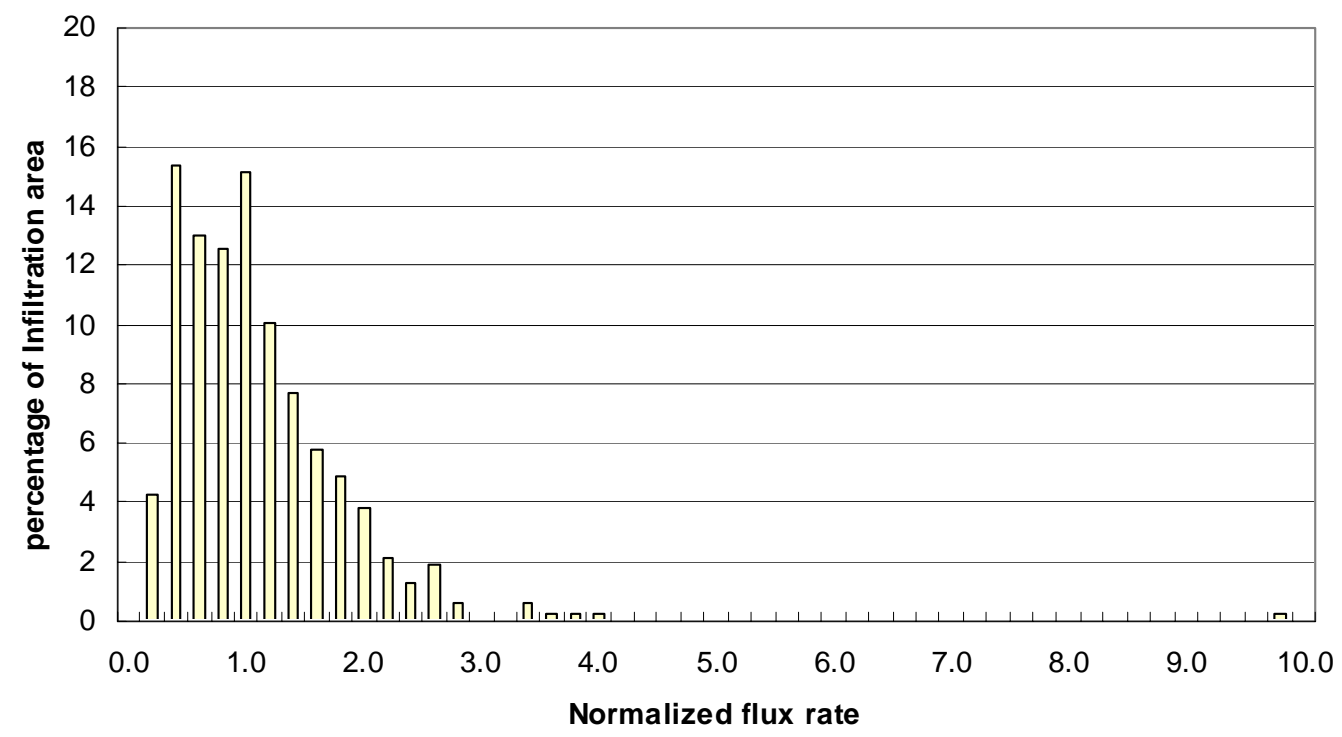

Figure 17 Area frequency and distribution of simulated percolation fluxes within the repository domain normalized to the mean glacial transition infiltration rate (17.02 $\mathrm{mm} / \mathrm{yr})$, simulated using the base-case parameter set with variations in fracture matrix van Genuchten parameter $\alpha$ (glaq $+\mathrm{aF}$ and glaq-aF) 


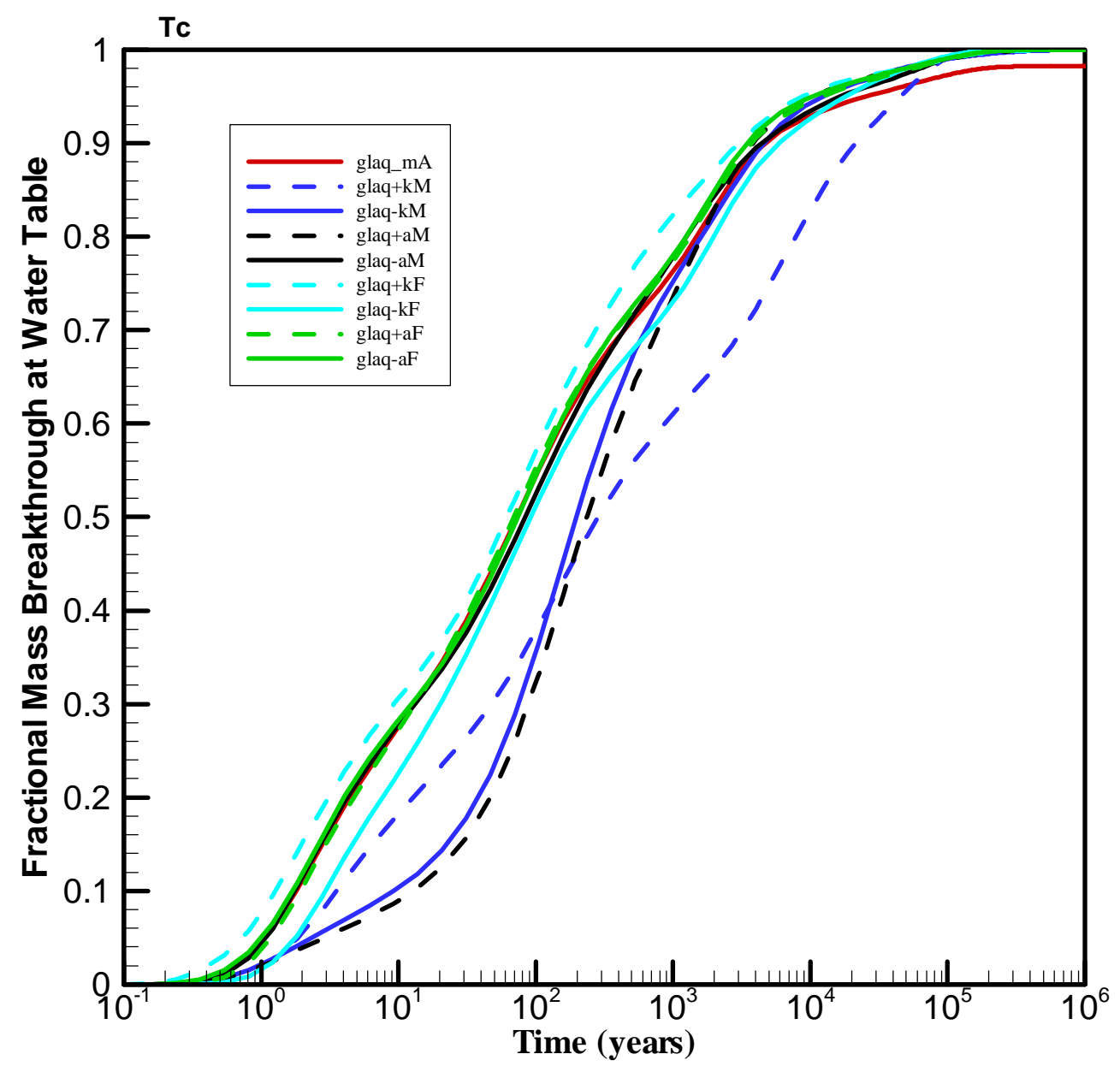

Figure 18 Comparisons of simulated breakthrough curves of cumulative conservative tracer (Tc) mass arriving at the water table, after release from the repository for the eight sensitivity simulation and base-case flow fields 


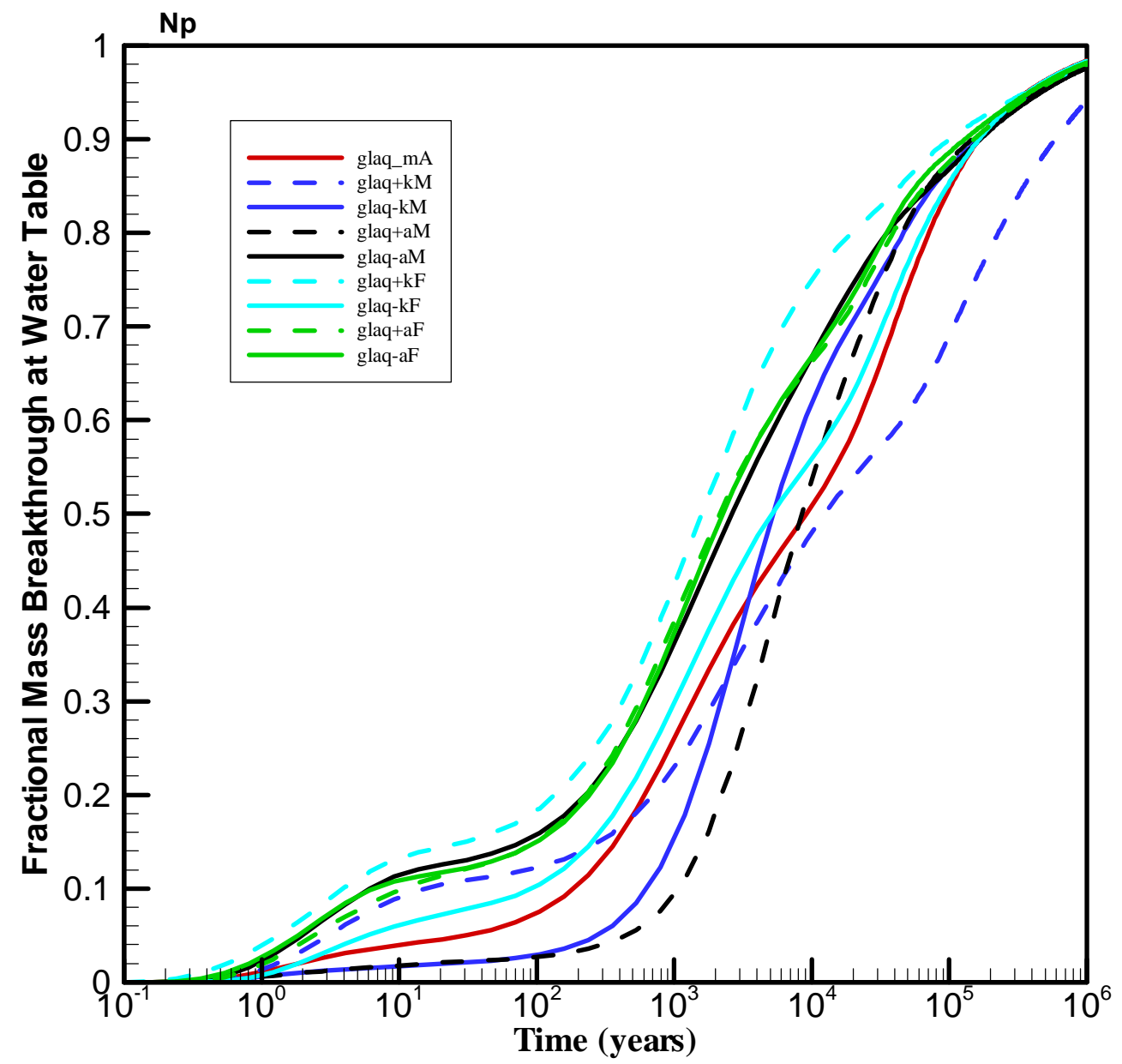

Figure 19 Comparisons of simulated breakthrough curves of cumulative reactive tracer $(\mathrm{Np})$ mass arriving at the water table, after release from the repository for the eight sensitivity simulation and base-case flow fields 